\title{
OCCUPANTS INTERACTION WITH ELECTRIC LIGHTING AND SHADING SYSTEMS IN REAL SINGLE-OCCUPIED OFFICES: RESULTS FROM A MONITORING CAMPAIGN
}

\author{
Pedro Correia da Silva ${ }^{a}$, Vítor Leal $^{\mathrm{a}}$, Marilyne Andersen ${ }^{\mathrm{b}}$ \\ ${ }^{a}$ Mechanical Engineering Department, Faculty of Engineering of the University of Porto (FEUP), Porto, Portugal \\ ${ }^{b}$ Interdisciplinary Laboratory of Performance-Integrated Design (LIPID), School of Architecture, Civil and Environmental \\ Engineering (ENAC), École Polytechnique Fédérale de Lausanne (EPFL), Switzerland
}

\begin{abstract}
This study presents a contribution to the characterization of occupants' behavior regarding the manual control of electric lighting in combination with shading control in offices. The procedure and monitoring results for eight single-occupied office spaces is described. The analysis of the collected data indicated that occupants kept electric lighting On during most of the monitoring period and, in average, that lower daylight illuminances led occupants to keep the lights On more frequently. It was also found that at times of arrival and departure the control patterns for lighting were mostly driven by occupation dynamics rather than by the environmental conditions. The results for the control patterns for shading systems concurrently showed that occupants frequently opened their shading device upon arrival, and, for half of the offices, closed it upon departure. On the other hand, at intermediate periods, the control patterns were mainly independent of occupation dynamics and dependant on environmental variables, but at very different degrees depending on the particular office considered. A further analysis of the control patterns for shading systems indicated that control patterns as found in the literature, which had been mostly derived from data obtained for offices in which the experiment required frequent actions from the occupant, correlated well with the experimental results only in predicting the absence of any shading control action, but were poor predictors of control actions (shading deployment).
\end{abstract}

Keywords: occupants behavior, electric lighting, shading, control, offices, monitoring campaign

\section{INTRODUCTION}

\subsection{Context}

Windows are one of the most complex determinants of the office environment, since they provide daylight, visual communication with the outside world, and often ventilation, but can simultaneously be a cause of thermal discomfort, glare, noise and distraction (Heschong, Aumann et al. 2003). Windows typically have a thermal U-value five to ten times higher than that of the opaque envelope where they are inserted (Levine and Ürge-Vorsatz 2007), and therefore have a very important direct contribution to the thermal balance and overall energy demand of our buildings, which, as known, can typically account for more than $50 \%$ (often more than $70 \%$ ) of the final energy demand for building types like office (Pérez-Lombard, Ortiz et al. 2008). Choosing the most adequate design or performance aspect for a window (e.g. Area, $\mathrm{U}$-value, Solar Factor of either the glazing or the shading device, or both) is therefore both a demanding and a complex task, as such choice will have to account for interior and exterior dynamics, and will have direct and indirect consequences on comfort and - in fact, as a result - on the overall energy demand for heating, cooling and lighting. It is nowadays widely recognized, for instance, that building design choice(s) that optimize building energy performance depend crucially on the building type and on the local climate (Clarke 2001; Bourgeois, Reinhart et al. 2005). Furthermore, the fact that building simulation has become easily available and more widely used within design practice makes it easier to compare design solutions. In some cases, the assessment of the energy performance with detailed building simulation is even required by local regulations for some building types (RSECE 2006). 
Published as: P. Correia da Silva, V. Leal, M. Andersen, Occupants interaction with electric lighting and shading systems in real single-occupied offices: Results from a monitoring campaign, Building and Environment, vol. 64, pp. 152-168, 2013 (DOI: http://dx.doi.org/ 10.1016/j.buildenv.2013.03.015)

An important and not to be overlooked factor in the process of assessment and 'optimization' of the energy performance is the interaction between occupants and lighting and shading systems. Building occupants tend to adjust them dynamically, mostly as a function of the indoor and outdoor environmental conditions and of the way these conditions impact their visual comfort perception. The drivers for control actions have typically been reported as being based on workplane illuminance (Hunt 1979; Roche, Dewey et al. 2000; Reinhart and Voss 2003; Reinhart 2004; Haldi and Robinson 2010), luminance in the field of view (Sutter, Dumortier et al. 2006; Inkarojrit 2008), glare indexes (Lee and Selkowitz 1995; Wienold 2009), incoming solar radiation (Inoue, Kawase et al. 1988; Newsham 1994; Lee and Selkowitz 1995; Foster and Oreszczyn 2001; Inkarojrit 2008; Mahdavi and Proglhof 2009) and/or dynamics of occupation (Pigg, Eilers et al. 1996; Mahdavi and Proglhof 2009). While the fact that the environmental variable chosen as the basis for the behavioral model does not necessarily imply that the behavioral patterns described are different, a closer observation of the models reveals considerable discrepancies (Correia da Silva, Leal et al. 2012; Van Den Wymelenberg 2012; O'Brien, Kapsis et al. 2013). The choice of different behavioral models in dynamic energy performance simulation of buildings was recently shown to have important consequences on best ranked alternatives (Correia da Silva, Leal et al. 2012). That paper proves that behavioral models that are either explicitly or implicitly used have a significant impact on the resulting energy performance values and, moreover, that the choice of one over another may result in inconsistent selections of the most efficient design alternative.

By analyzing how existing behavioral models were developed (Collins, Fisher et al. 1990; Boyce and Eklund 1995; Veitch and Newsham 1995; Bullow-Hube 2000; Velds 2000), we find that many of them were derived from monitoring campaigns that focused mainly on the assessment of the occupants' visual comfort and preferences. The behavior of the occupants was then inferred as being a consequence of occupants' preferences. Only more recently did monitoring campaigns directly aim at the characterization of actual occupants' behavior (Moore, Carter et al. 2002; Reinhart and Voss 2003; Inkarojrit 2005; Mahdavi and Proglhof 2009). In these latter campaigns, the monitoring of occupants behavior was mostly focused on electric lighting control, though several studies included shading aspects (Hunt and Crisp 1978; Pigg, Eilers et al. 1996; Reinhart and Voss 2003; Mahdavi and Proglhof 2009). The few campaigns focusing on the control of shading devices in real environments (with the building in operation and without significantly disturbing the occupants activities) considered only a very limited number of variables of the indoor environment (Reinhart and Voss 2003; Haldi and Robinson 2009). E.g.: the spatial distribution of indoor luminance throughout the day was not assessed (it had been assessed only in experiments involving significant occupant interaction with the experiment); experiments had short periods of effective days of observation (Inoue, Kawase et al. 1988); observation was not continuous throughout the day (Inkarojrit 2005); and/or the number of monitored rooms was very small (Hunt 1979; Reinhart and Voss 2003; Inkarojrit 2005).

In this context, it becomes important to increase the number of real-world offices, monitored under regular office work routines, and analyze occupant behavior as a function of the environmental conditions and the dynamics of occupation.. This paper presents the outcomes of an experiment that fulfills these requirements, based on the monitoring of eight single-occupied office spaces over time periods ranging from 35 to 65 days. The monitoring campaign was performed in the town of Porto, Portugal, which is located at the geographical coordinates $41^{\circ} 09^{\prime} \mathrm{N} 8^{\circ} 37^{\prime} \mathrm{W}$, with an Atlantic temperate climate. Besides expanding this type of investigation to a new climatic context, this work includes a significant extension of the monitoring periods for campaigns on real work environments compared to previous studies, with minimal if any disturbance to the normal activities; a wider range of environmental variables was also considered, with a specific emphasis on the luminance distribution in the field of view while resorting to a high frequency of observation and data collection.

\subsection{Research questions}

The analysis of the experimental data gathered during the monitoring campaign and related to the control pattern for electric lighting was structured and performed to address a set of key research questions. These were:

1. What daylight illuminance ranges do we find in offices? 
Published as: P. Correia da Silva, V. Leal, M. Andersen, Occupants interaction with electric lighting and shading systems in real single-occupied offices: Results from a monitoring campaign, Building and Environment, vol. 64, pp. 152-168, 2013 (DOI: http://dx.doi.org/ 10.1016/j.buildenv.2013.03.015)

Illuminance is one of the requirements for visual comfort most referred to in the literature. To characterize its temporal and spatial distribution both in terms of total illuminance and daylight illuminance, it is therefore essential to try to correlate it with observed control patterns.

2. Does the observed electric lighting state depend on the observed daylight illuminance?

Since daylight illuminance is assumed to be one of the main parameters driving electric lighting control in the literature, the influence of daylight illuminance on the state of the electric lighting has to be evaluated during occupied periods.

3. Do observed control patterns for electric lighting vary considerably with occupation dynamics and/or in interaction with daylight availability?

Some literature sources indicate that electric lighting is controlled based on occupation dynamics (arrival, stay and departure) (Hunt 1979; Pigg, Eilers et al. 1996; Inkarojrit 2005). To address this issue, data must be divided according to occupation dynamics. The influence of daylight illuminance on control patterns can then be analyzed for each occupation period.

4. Are daylight illuminance and duration of absence significantly correlated to electric lighting control actions? According to the literature, the most influential variables in terms of triggering electric lighting control actions are workplane illuminance and occupation dynamics (presence/absence from office). To assess if the experimental data collected supports this hypothesis, a statistical method (logistic regression) was applied for the computation of probabilistic models to predict observed control patterns and the analysis of possible correlations between the manual control of electric lighting, daylight illuminance at the workplane and duration of absence.

Regarding the control patterns for shading systems, the key questions that drove the analysis were:

5. Do control patterns for shading systems vary considerably with occupation dynamics?

The purpose of this question is to assess whether control patterns for shading systems differ according to the period of occupation (arrival, stay and departure).

6. Do variations in the transmitted direct solar radiation hitting the workplace influence the shading control actions? Transmitted direct solar radiation hitting the workplace is indicated in the literature as one of the main reasons triggering occupants to close or adjust the shading system. Starting from this hypothesis, the moments of the day where significant variations in terms of direct solar radiation were observed were analyzed further to assess their impact on occupants behavior.

7. Which environmental variables are statistically significant for the control of the shading systems?

Statistical methods - multiple and logistic regressions - were applied to explore the relationships between the observations and the environmental variables. The main purpose of this analysis was to select, from all the environmental variables, the ones that were the most robust predictors for the shading systems' control patterns.

8. Do observed shading states agree with those suggested by previously published shading control patterns? Several patterns for shading system control can be found in the literature, which claim to reproduce/predict their state based lighting or other environmental conditions (inferably through occupants behaviour as answer to the environmental conditions). This question thus aims to assess to what extent observed shading states agree with the main control patterns suggested in the literature.

9. Do observed control events occur as predicted by the control conditions for shading states?

Since there are some published patterns of shading control that state which variables - and which threshold values for these variables - occupants are responsive to, it is important to assess whether the observed occupant actions are in agreement with the observed values of such variables (control conditions) or not.

10. Which share of shading control actions are simultaneous with lighting control actions?

This research question explores the possibility of simultaneous control actions in both shading and electric lighting systems. Control patterns are further analyzed whenever both systems are used simultaneously, for the three identified periods of occupation dynamics (arrival, stay and departure). 
Published as: P. Correia da Silva, V. Leal, M. Andersen, Occupants interaction with electric lighting and shading systems in real single-occupied offices: Results from a monitoring campaign, Building and Environment, vol. 64, pp. 152-168, 2013 (DOI: http://dx.doi.org/ 10.1016/j.buildenv.2013.03.015)

11. How do observed control patterns compare with behavioral models found in the literature?

In the literature, there are several criteria and behavioral models that claim to reproduce occupants control patterns for lighting and shading systems. The control patterns observed during this monitoring campaign are thus compared to four control criteria previously suggested in the literature so as to better understand their scope and limits of application.

\section{MONITORING PROCEDURE AND CONDITIONS}

\subsection{Experimental setup}

The identification of the variables to be monitored in order to assess occupants' behaviour regarding the control of electric lighting and of shadings was derived from a bibliographic review (Velds 2000; Velds and Christoffersen 2001; Christoffersen and Wienold 2003), with a specific focus on the environmental parameters involved in existing behavioral models and control patterns (Correia da Silva, Leal et al. 2012). In the literature, the variables considered in the monitoring and assessment of the occupants' control patterns are, typically: workplane (daylight) illuminance (Hunt 1979); average window luminance (Sutter, Dumortier et al. 2006); maximum window luminance and background luminance (Inkarojrit 2008); DGI (Lee and Selkowitz 1995); DGP (Wienold and Christoffersen 2006); vertical transmitted direct solar radiation (Inoue, Kawase et al. 1988); vertical incident global solar radiation (Foster and Oreszczyn 2001); and, duration of occupation/absence (Pigg, Eilers et al. 1996; Mahdavi and Proglhof 2009). In the present study, it was decided that all parameters would be monitored so as to later assess to what extent the observed behaviour agrees with the behaviour suggested by each model. From this process, the following variables were identified:

- Workplane illuminance (direct measurement): The illuminance of the workplane was measured using three illuminance sensors. The sensors were located on the desk, facing upwards; two of them were positioned on the edges of the desk and the third in a central position. The workplane illuminance considered in the results analysis is the average of the illuminances measured by these three sensors; This procedure was adopted to reduce the potential influence of the occupant regular activity on the illuminance measured by each individual sensor. The illuminance sensor used has a resolution of 1.5 lux and an accuracy of $3 \%$ (Skyelnstruments 2010).

- Workplane daylight illuminance (post-processing of workplane illuminance): The workplane daylight illuminance was calculated from the difference between total workplane illuminance (as measured above) and workplane illuminance due to electric lighting only. The latter was measured manually at night time, in the absence of daylight (night light pollution effects were negligible);

- Average window luminance and background luminance (post-processing of the luminance distribution assessment): The luminance distribution of the window and interior surfaces was assessed using a calibrated camera and a software to post-process the sets of photographs, captured according to a pre-defined exposure setting sequence every 20 minutes (Dumortier, Coutelier et al. 2005) so as to produce HDR luminance maps (Inanici 2006). The camera used was a Canon EOS50D coupled with a fisheye lens (Canon 2009), computercontrolled with fully adjustable photographic settings. A C application was developed to control the schedule, number and camera settings, which allowed the control of the camera from the PC without any external intervention. The camera was in a fixed position, as close as possible to the occupants' head and with a view direction aligned with the normal work position (see Figure 1);

- $\quad$ DGI and DGP (post-processing of luminance distribution): The Daylight Glare Index (DGI) (Velds and Christoffersen 2001) and the Daylight Glare Probability (DGP) (Wienold and Christoffersen 2006) were computed directly from their definition, based on the measured luminance distribution in the occupant's field of view from his/her regular work position and viewpoint; 
Published as: P. Correia da Silva, V. Leal, M. Andersen, Occupants interaction with electric lighting and shading systems in real single-occupied offices: Results from a monitoring campaign, Building and Environment, vol. 64, pp. 152-168, 2013 (DOI: http://dx.doi.org/ 10.1016/j.buildenv.2013.03.015)

Vertical transmitted direct solar radiation and vertical incident global solar radiation (post-processing of the global transmitted solar radiation measurement): The global vertical solar radiation transmitted through the window was measured with a pyranometer, set-up at the bottom of and against the glazing on the inside, facing outwards (see Figure 1). The pyranometer was new, and according to the manufacturer presented a resolution of $0.1 \mathrm{~W} / \mathrm{m} 2$ and an accuracy of $4.5 \%$ (Kipp\&Zonen 2009). The incident global solar radiation was then derived from it, accounting for glazing transmittance. The glazing transmittance itself was measured under overcast sky conditions, using a portable luxmeter. The direct solar radiation transmitted through the glazing was assessed by subtraction, based on measured global transmitted solar radiation and diffuse transmitted solar radiation. The diffuse transmitted solar radiation was derived from the measurements of the outdoor horizontal diffuse solar radiation and the glazing transmittance, assuming an isotropic sky (Muneer 2004);

- Ambient temperature (direct measurement): A thermometer, mounted next the calibrated camera, measured the ambient temperature of each office. The thermometer has a resolution of $0.001^{\circ} \mathrm{C}$ and an accuracy of $0.4 \%$ (ThiesClima 2010);

- Duration of absence (post-processing of the presence measurement): The presence of the occupant was detected by a motion sensor, located next to the acquisition system or the calibrated camera and directed towards the normal occupant work position (see Figure 1);

- Electric lighting state (analysis of the photographs taken for luminance distribution assessment): The state of electric lighting (On/Off) was identified using techniques of pattern recognition (Wienold and Christoffersen 2006). Through an algorithm developed in Matlab (MathWorks 2009), the luminance map of each monitoring time-step was analyzed. The average luminance of the pixels of the lamp area was compared to a pre-defined luminance threshold, based on the analysis of a set of luminance maps. When the average luminance of the lamp area exceeded the threshold, it was concluded that the lamp was turned On. The method revealed to be particularly reliable in spaces lit by direct electric lighting. In environments with indirect electric lighting, the detection of the lighting state presented some limitations especially when the wall and the ceiling presented high luminances $(>200 \mathrm{~cd} / \mathrm{m} 2)$. In these specific cases, the state of the electric lights was confirmed visually;

- Shading deployment (analysis of the photographs): The shading deployment - percentage of the window covered by the vertical projection of the shading on the window - was calculated using the slats angle and the vertical position of the shading. The slats angle and the vertical position, in each monitoring time-step, were identified by a manual visual analysis of the pictures captured to compute luminance maps, that were compared to reference pictures taken beforehand under precisely controlled conditions: these consisted of pictures of eight shading vertical positions and pictures of seven shading slat angles, which basically covers the overall range of possible shading positions. The use of image processing techniques for blinds position estimation was considered during the planning of the experiment and in the initial analysis of the data. However, in practice the image patterns recognition techniques weren't as accurate as expected - it was found that there were too many variables to evaluate (like vertical blinds positions, slats tilt, outdoor landscape) which made the automated recognition of the blind position not reliable enough.

Figure 1 shows the global arrangement of the instrumentation described above for Office 4 . The main elements of the instrumentation are identifiable in the picture: illuminance sensors, pyranometer, calibrated camera, motion sensor and data acquisition system, which was constituted by a USB acquisition board connected to a notebook.

The measurement and registration of the outdoor meteorological conditions were performed by a weather station located in the Faculty of Engineering of the University of Porto, Portugal (LFC 2011). Since the monitored offices were all located nearby the LFC (maximum distance $1.5 \mathrm{~km}$ ), weather conditions recorded at the station were considered relevant for the office data analysis. 
Published as: P. Correia da Silva, V. Leal, M. Andersen, Occupants interaction with electric lighting and shading systems in real single-occupied offices: Results from a monitoring campaign, Building and Environment, vol. 64, pp. 152-168, 2013 (DOI: http://dx.doi.org/ 10.1016/j.buildenv.2013.03.015)

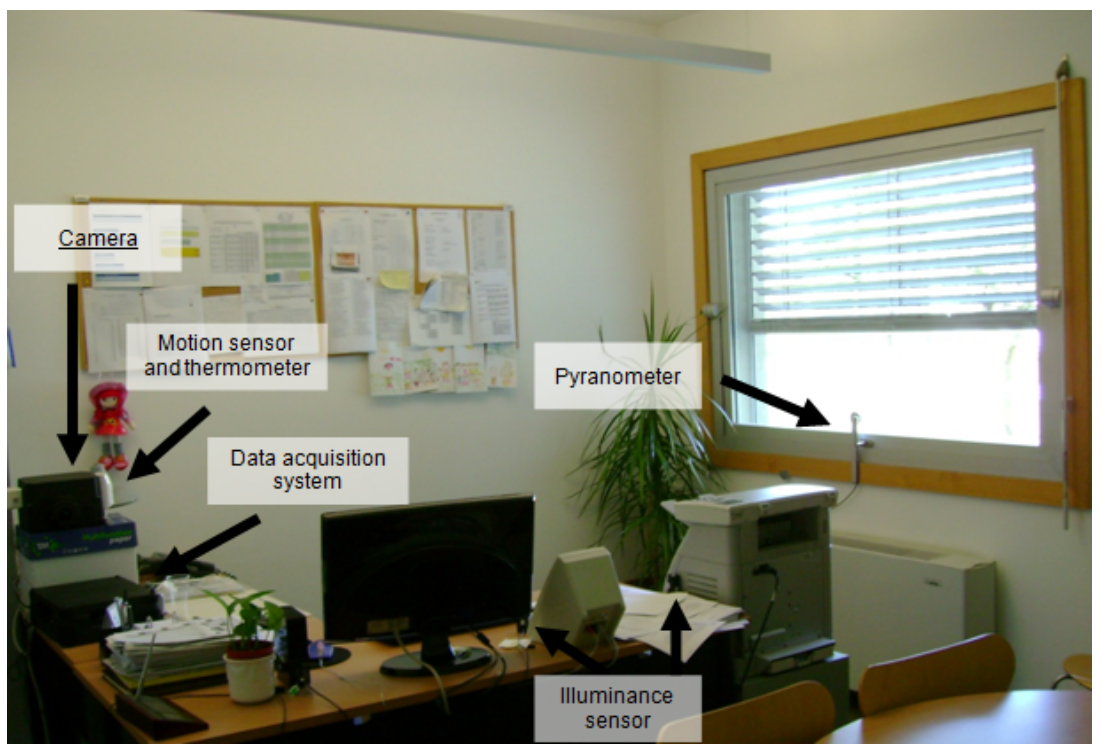

Figure 1: Typical layout of the monitoring instrumentation installed

\subsection{Offices monitored}

The characterization of the occupants' behaviour was performed in eight single offices during an average period of two months. The monitoring duration was established as compromise between the global period available (one year) and the need to observe a diversity of offices during a reasonable time each, though with a limited availability of instrumentation. Two of the key requirements in the choice of the offices were that: 1) They are not facing North as an attempt of having a wide range of environmental conditions and if possible direct solar radiation hitting the windows, both of which would be unlikely to obtain in north-facing windows during occupation hours; additionally, the measurement equipment and time was somewhat limited, and it was decided to focus on the (likely) higher dynamics environments. 2) They have a blinds shading system that allows a gradual occlusion of the window between nearly all open to nearly all closed, as decided by the occupant. All the selected offices are part of the University of Porto Campus: in the Faculty of Psychology and Educational Sciences (Offices 1 to 5), and in the library of the Faculty of Engineering (Offices 6 to 8 ). This allowed a close follow up of the monitoring. All offices are occupied by administrative personnel that had no prior knowledge of the scientific problem under analysis. The main characteristics of the offices layouts, regular occupants and monitoring period are shown in Table 1 and illustrated in Figure 2. All the offices present similar interior architecture. The main differences between the offices are related to the orientation and features of the window and shading systems:

- window orientation: Offices 1 to 2 are West oriented, Offices 3 to 5 are East oriented and Offices 6 to 8 are South oriented;

- $\quad$ window size: window of Offices 1 to 5 has an area of 1.57 square meters while window of Offices 6 to 7 has an area of 3.92 square meters;

- visual glazing transmittance: in Offices 1 to 5 the transmittance is $77 \%$ and in Offices 6 to 7 the transmittance is $13 \%$;shading system: window of Offices 1 to Office 5 is shaded by external blinds (no horizontal overhangs nor vertical fins) and window of Offices 6 to 8 has internal blinds and external horizontal overhangs and vertical fins (represented in Figure 2). 
Published as: P. Correia da Silva, V. Leal, M. Andersen, Occupants interaction with electric lighting and shading systems in real single-occupied offices: Results from a monitoring campaign, Building and Environment, vol. 64, pp. 152-168, 2013

(DOI: http://dx.doi.org/ 10.1016/j.buildenv.2013.03.015)

Table 1: Main characteristics of the monitored offices, the correspondent occupant and the monitoring period

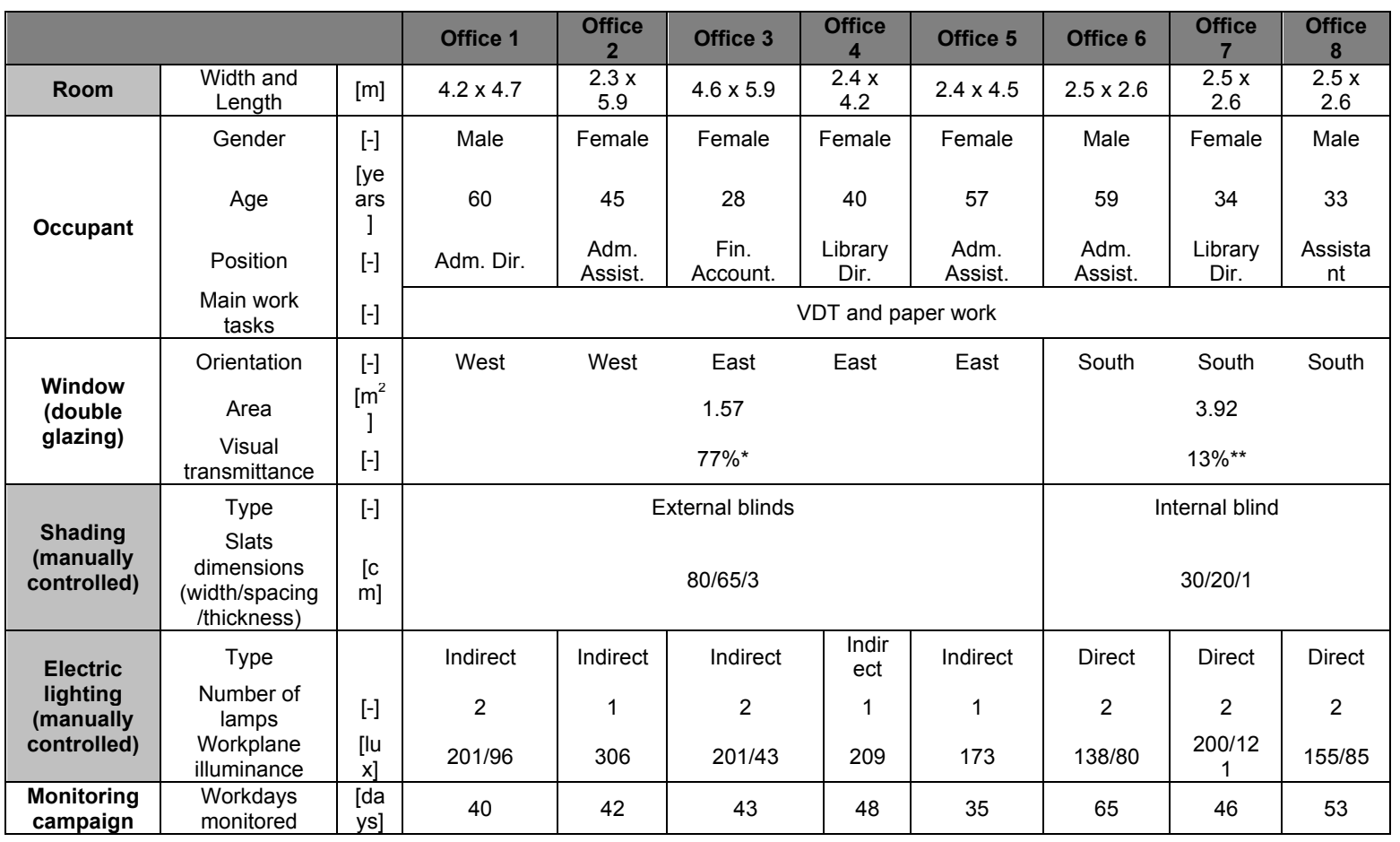

*clear double glazing $\quad$ ** double glazing with thin coating external layer, applied to increase solar protection

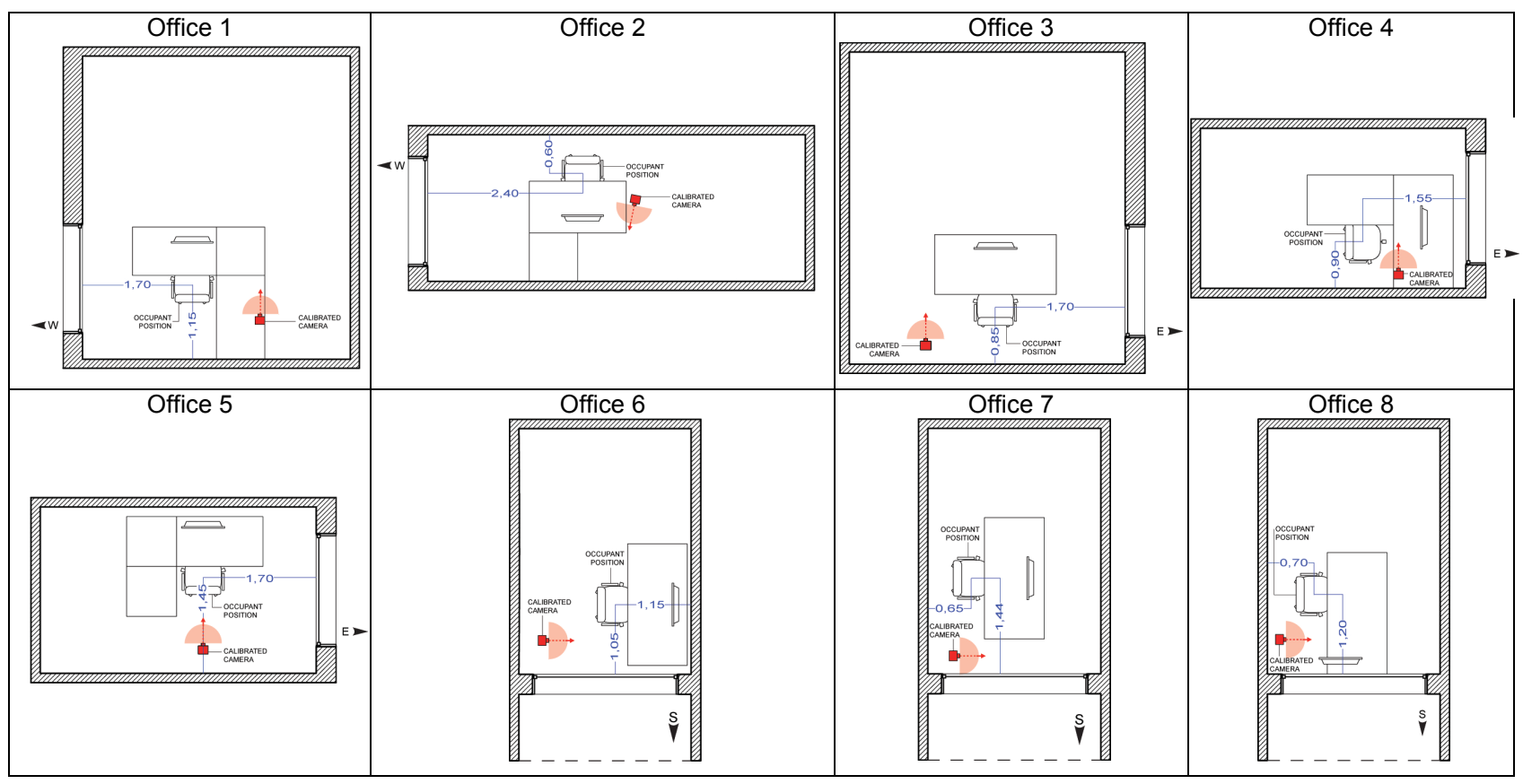

Figure 2: Schematic plans of the eight offices, with the indication of the camera and workplace position

At the beginning of the monitoring, details regarding the monitoring set-up and its purpose were explained to office occupants. They were told to interact with electric lighting and shading systems as they usually would, and to avoid any direct interaction with the instrumentation running. The instrumentation was mounted so that it wouldn't interfere with the occupant's position or task. A multiple-choice paper questionnaire was also provided to encourage occupants to identify the reasons that motivated them to adjust the electric lighting state or the shading device's position, on a voluntary basis. In the end, since occupants did actually not fill it, these questionnaires were disregarded. The consideration of equestionnaires (e.g prompted by changes in environmental conditions detected by the instrumentation) were initially ruled out because they were considered too intrusive and potentially disruptive of the occupants activities or "natural" behavior. 
Published as: P. Correia da Silva, V. Leal, M. Andersen, Occupants interaction with electric lighting and shading systems in real single-occupied offices: Results from a monitoring campaign, Building and Environment, vol. 64, pp. 152-168, 2013 (DOI: http://dx.doi.org/ 10.1016/j.buildenv.2013.03.015)

\section{RESULTS}

The experimental setup in the eight real offices allowed the continuous registration of the environmental variables identified above over the monitoring period, with a sampling rate of 30 seconds, except picture capture (necessary to compute the luminance maps), which were taken with a sampling rate of 20 minutes. Due to limitations on the storage of photographs, the analysis was done in 20 min blocks. The 30 second time step thus enabled to get 60 measurements per block, which was considered representative while also keeping enough dynamics for a thorough analysis. The results presented in this section were processed by averaging the measured data for all environmental variables over the past 20 minutes so as to reduce the dataset. As referred to in section 1.2, the analysis of the data was structured and performed in order to address a set of key-research questions. This chapter is organized along these key-questions, with a section dedicated to each of them.

\subsection{What daylight illuminance ranges do we find in offices?}

The measurement of the workplane illuminance allowed to characterize the availability of daylight illuminance during the monitored occupation period based on the most commonly used illumination metric. Four reference illuminance thresholds were selected - 100 lux, 300 lux, 500 lux and 2000 lux - to analyze the results: the reference illuminances of 100 lux and 2000 lux were selected considering the minimum and maximum useful daylight illuminances proposed by Nabil (Nabil and Mardaljevic 2005), and the illuminances of 300 lux and 500 lux are described in the literature as recommended levels of workplane illuminance that should be provided in offices, depending on the performed task (Rea 2000; Boyce and Raynham 2009).

The distribution of daylight illuminance levels of the eight offices is shown in Figure 3. The table attached to the chart presents the orientation, glazing transmittance and average shading deployment during the monitoring period and the desk position within each office is indicated in Figure 2.

The majority of offices presented daylight illuminance levels under 500 lux during most of the time. Furthermore, in half of the offices - Office 1 , Office 4 , Office 5 and Office 6 - the percentage of time that daylight illuminance $\left(I_{D}\right)$ was lower than 300 lux represented more than $50 \%$ of the occupation period, reaching almost $100 \%$ of the time in Office 6 . It is important to note, however, that these daylight illuminance values take into account the effect of the actual shading positions, and are thus often as result of occupant behavior.

The majority of monitored offices had, during most of the monitoring period, daylight levels lower than what the literature indicates as the minimum recommended workplane illuminance. Observed differences between the eight offices are mainly driven by control patterns for shadings, as will be seen in subsections 3.4 to 3.7 but also by architectural features of the offices, namely glazing transmittance, window size and orientation.

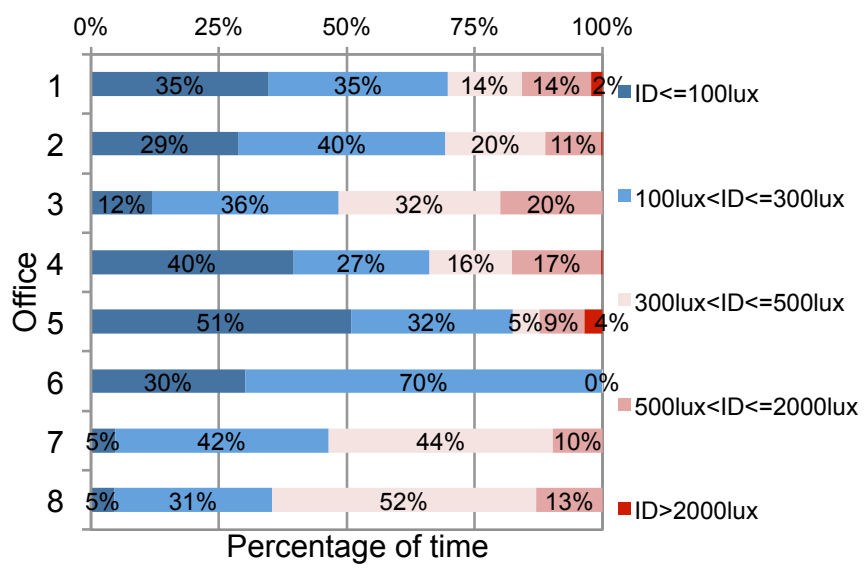

\begin{tabular}{|c|c|c|c|c|}
\hline Office & $\begin{array}{c}\text { Orienta } \\
\text { tion }\end{array}$ & $\begin{array}{l}\text { Glazing } \\
\text { transmitt } \\
\text { ance }(\%)\end{array}$ & $\begin{array}{c}\text { Windo } \\
\text { w area } \\
(\mathrm{m} 2)\end{array}$ & $\begin{array}{c}\text { Shading } \\
\text { deploym } \\
\text { nt (ave) } \\
(\%) \\
\end{array}$ \\
\hline 1 & \multirow{2}{*}{ West } & \multirow{5}{*}{77} & \multirow{5}{*}{1.57} & 31 \\
\hline 2 & & & & 45 \\
\hline 3 & \multirow{3}{*}{ East } & & & $<1$ \\
\hline 4 & & & & 70 \\
\hline 5 & & & & 54 \\
\hline 6 & \multirow{3}{*}{ South } & \multirow{3}{*}{13} & \multirow{3}{*}{3.92} & 20 \\
\hline 7 & & & & 50 \\
\hline 8 & & & & 25 \\
\hline
\end{tabular}

Figure 3: Temporal distribution of the average desktop daylight illuminance (ID) in each of the 8 offices and features influencing availability of daylight illuminance 
Published as: P. Correia da Silva, V. Leal, M. Andersen, Occupants interaction with electric lighting and shading systems in real single-occupied offices: Results from a monitoring campaign, Building and Environment, vol. 64, pp. 152-168, 2013 (DOI: http://dx.doi.org/ 10.1016/j.buildenv.2013.03.015)

\subsection{Does the observed electric lighting state depend on the observed daylight illuminance?}

The state of the electric lighting (On / Off), was correlated to daylight illuminance levels, with results shown in Figure 4.

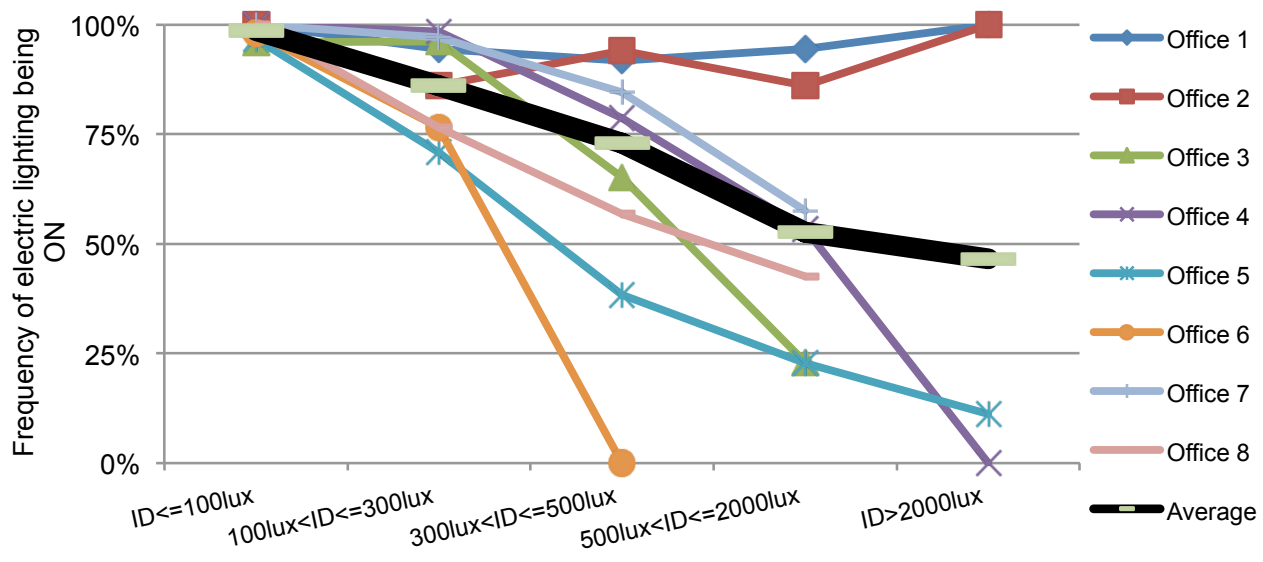

Daylight illuminance range

Figure 4: Summary of the electric lighting state, by daylight illuminance range (ID), for each of the 8 offices. during occupied period

The analysis of Figure 4 and the distribution of daylight illuminance in Figure 3 suggests the following:

i. In all the offices, electric lighting was switched On during $83 \%$ of the monitoring period;

ii. In average, the daylight illuminance was $447 \mathrm{lux}$ when electric lighting was switched Off (M=447, S.D. $=338$ and $n=783$ ) while the daylight illuminance was 229 lux when electric lighting was switched On (M=229, S.D.=286 and $n=3731$ );

iii. Nearly all time when available daylight was lower than 100 lux, electric lighting was switched On (only Office 5 presented a few occasions with daylight illuminance below 100 lux and electric lighting switched off);

iv. As previously stated, some of the offices presented a considerable percentage of time with daylight illuminances lower than 300 lux, and electric lighting mostly On;

v. When daylight illuminances were between 300 and 500 lux, significant periods with electric lighting switched Off were observed. The predominant state was still "On" in all offices except Office 5.

vi. When daylight levels were between 500 and 2000 lux, the "On" state for electric lighting was only predominant in Offices 1 and 2. Offices 4 and 7 presented an equal distribution of "On" and "Off" states, while the other 4 offices presented a predominance of the "Off" states.

vii. There were few occasions where levels of daylight illuminance higher than 2000 lux were observed in Offices 1, 2, 4 and 5, and never in the other offices. Electric lighting in Offices 1 and 2 was - in those cases - always switched "On", while electric lighting of Offices 4 and 5 was always switched "Off".

In summary, the analysis of the data seems to show that:

i) There are two types of occupants: those that do not react to natural environmental conditions and those who do, which seem - from our small sample size - to represent the majority (6 out of the 8 monitored occupants);

ii) For occupants that are sensitive to the natural environmental conditions, it seems that manually controlled electric lights will only be switched "Off" during a significant part of the time if daylight levels are above 500 lux.

\subsection{Do observed control patterns for electric lighting vary considerably with occupation dynamics and/or in interaction with daylight availability?}

A control patterns analysis was performed by identifying events of electric lighting control. This analysis was divided into three focus periods, derived from occupation dynamics:

i. Arrival periods, when the occupant arrives in the office after an absence of three hours or more (typically morning arrival); 
Published as: P. Correia da Silva, V. Leal, M. Andersen, Occupants interaction with electric lighting and shading systems in real single-occupied offices: Results from a monitoring campaign, Building and Environment, vol. 64, pp. 152-168, 2013 (DOI: http://dx.doi.org/ 10.1016/j.buildenv.2013.03.015)

ii. Intermediate periods (neither arrival nor departure period), which are themselves divided into continuous occupation periods and periods with intermittent (temporary) absences;

iii. Departure periods, just before the occupant leaves the office for an absence of three hours or more (typically end of working day).

The choice of analyzing these three focus periods separately was based on bibliographic references that point out that moments of arrival and departure are particularly prone to control actions (Hunt 1979; Pigg, Eilers et al. 1996), as opposed to continued occupancy or temporary absences where control actions were not as frequently observed. The three hours threshold represents a reasonable timeframe within which absences perceived by occupants as temporary exceptions to an otherwise continuous occupation - such as lunch and coffee breaks as well as typical meetings - can fit. This approach will also allow us to determine which share of the control actions is in fact linked to arrivals or departures. Electric lighting was switched On in $77 \%$ of the identified arrival periods ( $n_{\text {Observations }}=350$ )(electric lighting was always Off before such periods). To determine the extent to which daylight availability had an impact on this control pattern, the frequency of electric lighting switching "On" was computed against daylight illuminance measured just prior to the occupant's first arrival. This frequency is presented in Figure 5 for each of the offices. Results show that the frequency of electric lighting switching "On" decreases as daylight illuminance increases. The influence of daylight illuminance is particularly significant for extreme conditions: on average, occupants switched lights On in $95 \%$ of the cases where daylight illuminance was lower than 100 lux, and in $0 \%$ of the cases where daylight illuminance was higher than 2000 lux. It is important to note, however, that offices generally presented low daylight illuminances on arrival making the data set from which Figure 5 is derived significantly uneven amongst the ranges of daylight illuminance.

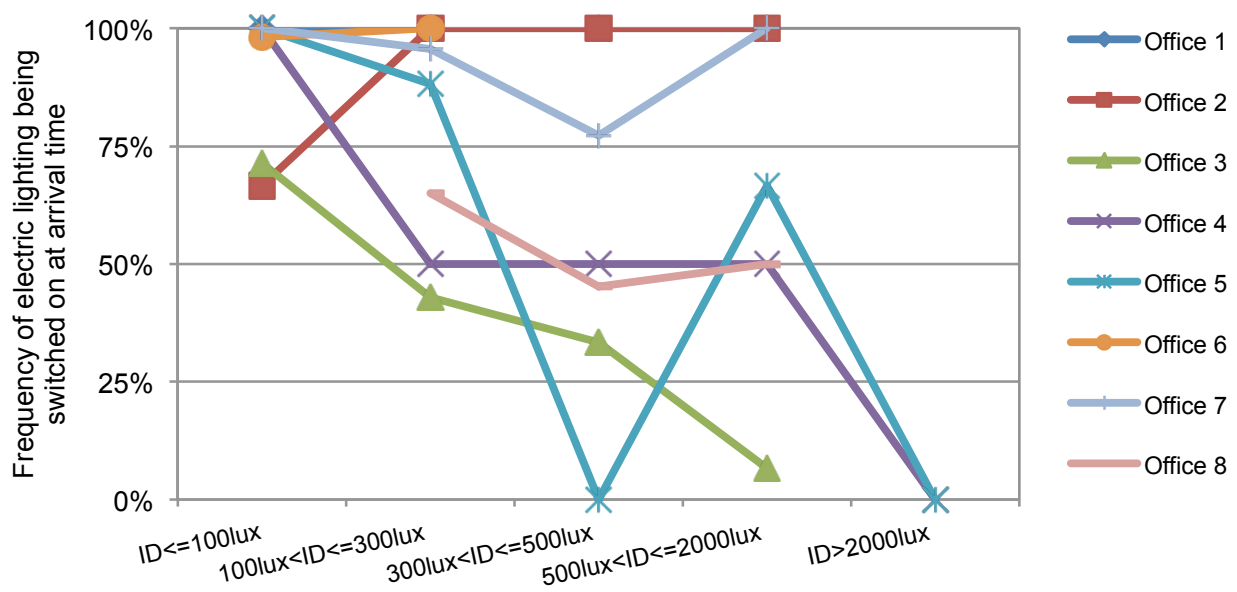

Figure 5: Frequency of the occupant switching electric lighting On upon arrival, as a function of daylight illuminance.

During intermediate periods, most office occupants leave the room for short absences. The behaviour of occupants at such intermediate times was analyzed considering all the occasions where occupants either temporarily left the office, returned to it, or didn't leave. Several bibliography references (Pigg, Eilers et al. 1996; Reinhart and Voss 2003; Inkarojrit 2005; Mahdavi and Proglhof 2009) identify the arrival or departure moments as privileged occasions to change the state of electric lighting.

Figure 6 shows, for each office, the percentage of events that were associated to temporary absences at intermediate times. On average, $79 \%$ of the all such events were related to temporary absences. These results hence confirmed that arrival and departure times were, even for short beaks, distinctly privileged moments for lighting control actions. On average, electric lighting was switched Off in $35 \%$ of the occasions ( $n_{\text {observations }}=509$ ) it was previously On just before the occupants left the office. This average is however constructed from a wide diversity of occupant profiles, ranging from occupants that turn lights Off nearly every time they leave the office (e.g. occupant 8) to occupants that only rarely switch lights Off at all (e.g. occupants 2 and 7), and seem to be independent of the daylight availability at the time. Such switching Off events were indeed in some offices more often linked to low illuminances (offices 1 and 8), whereas in others it was to high ones (offices 3 to 7). Unsurprisingly, these results tend to show that occupant behavior when leaving the office is driven by occupant profile more than by daylight illuminance. As far as the behaviour when returning to the 
Published as: P. Correia da Silva, V. Leal, M. Andersen, Occupants interaction with electric lighting and shading systems in real single-occupied offices: Results from a monitoring campaign, Building and Environment, vol. 64, pp. 152-168, 2013 (DOI: http://dx.doi.org/ 10.1016/j.buildenv.2013.03.015)

office after a temporary absence is concerned, occupants switched electric lighting On in $56 \%$ of the occasions ( $\mathrm{n}_{\text {observations }}=591$ ) it was previously Off.

Figure 8 summarizes the observed control patterns as a function of daylight illuminance. Results show that control patterns were directly influenced by daylight availability since seven of the eight occupants switched electric lighting On more frequently for lower daylight illuminances - in average, electric lighting was switched On in $93 \%$ of the occasions with daylight illuminances lower than 100 lux, decreasing to $77 \%$ for daylight illuminances between 100 and 300 lux and to $61 \%$ for daylight illuminances between 300 and 500 lux, reaching the minimum frequency of $28 \%$ for daylight illuminances higher than 500 lux.

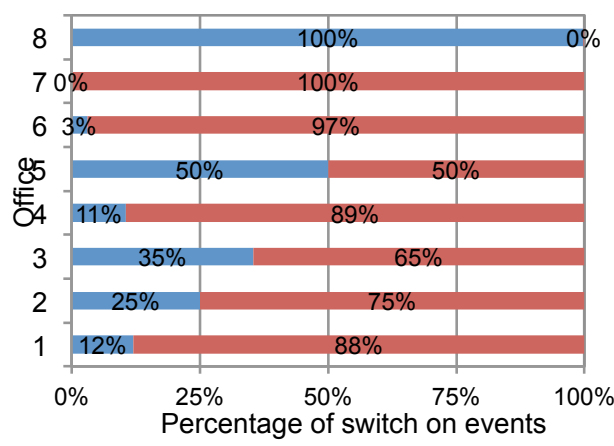

- Switch On events not associated to occupant absence - Switch On events associated to occupant absence

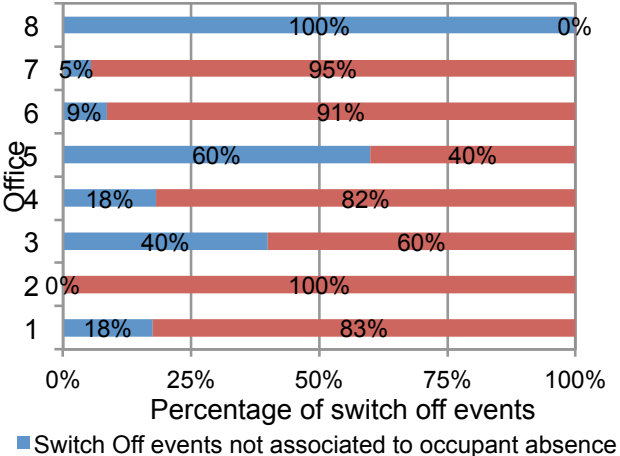

(b)
- Switch Off events not associated to occupant absence

- Switch Off events associated to occupant absence

Figure 6: Split of switch on (a) and off (b) events between "associated to occupant absence" and "not associated to occupant absence" in each of the 8 offices during intermediate time
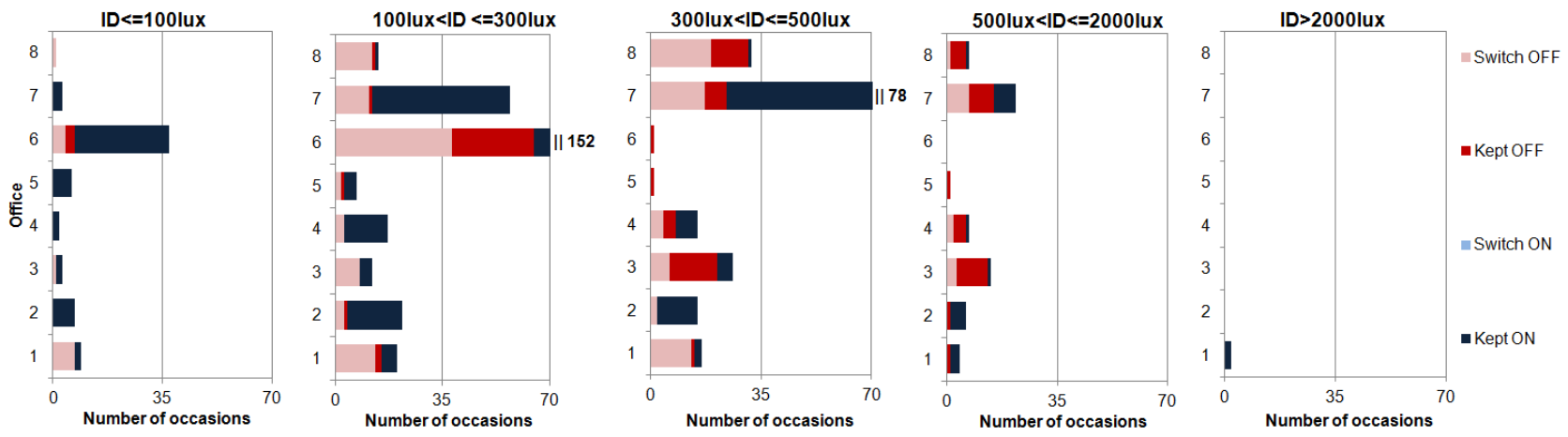

Figure 7: Behaviour of occupants when leaving the office for short breaks, as a function of daylight illuminance (ID)
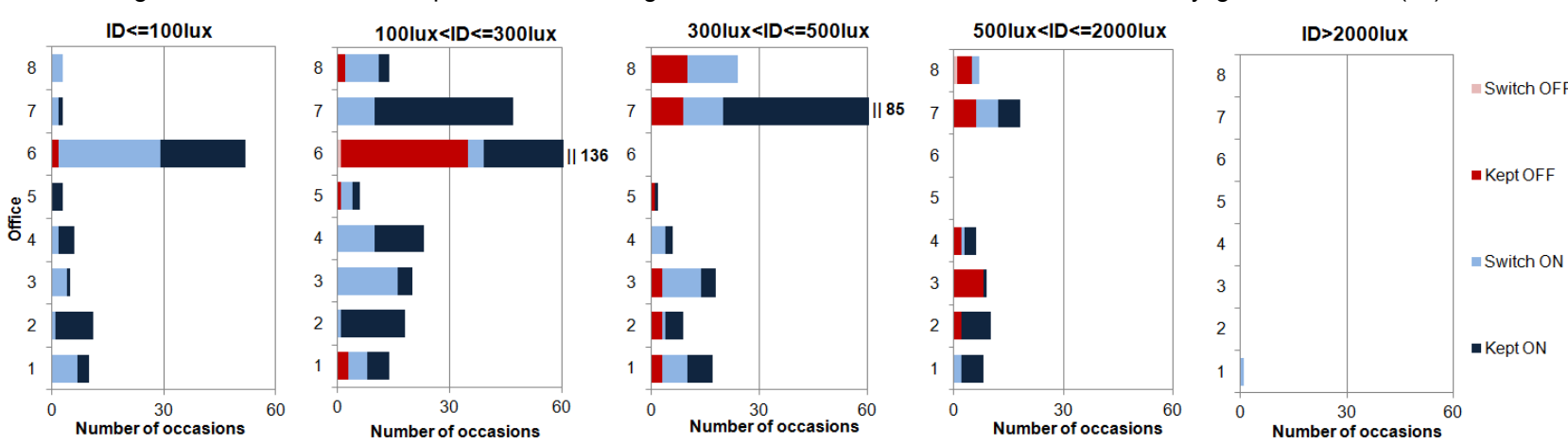

Figure 8: Behaviour of occupants when returning to the office from short breaks as a function of daylight illuminance (ID)

Experimental data show that electric lighting was controlled very rarely when occupants remained continuously in the office. Table 2 indicates the number of electric lighting events during intermediate periods not associated with absences. During the monitoring campaign, and considering all the offices, electric lighting was adjusted, on average, only twice every 10 workdays during continuous office occupation.

In order to analyze the influence of daylight illuminance on these adjustment events, experimental data were disaggregated according to the previously introduced reference illuminance ranges (see Figure 9). Results show that 
Published as: P. Correia da Silva, V. Leal, M. Andersen, Occupants interaction with electric lighting and shading systems in real single-occupied offices: Results from a monitoring campaign, Building and Environment, vol. 64, pp. 152-168, 2013 (DOI: http://dx.doi.org/ 10.1016/j.buildenv.2013.03.015)

switch On events are actually dependent on daylight illuminance, particularly for the illuminances lower than 300 lux, whereas daylight illuminance had no significant impact on switch Off events.

As far as departure periods are concerned, all the occupants switched electric lighting Off in $97 \%$ of the time $\left(n_{\text {Observations }}=265\right.$ ) they left the office for absences longer than three hours (the end of the day in the overwhelming majority) and the electric lighting was previously On

Table 2: Number of electric lighting events not associated with absences during intermediate time, by office

\begin{tabular}{cccc}
\hline & Number of workdays monitored & Switch ON & Switch OFF \\
\hline Office 1 & 40 & 3 & 7 \\
Office 2 & 42 & 1 & 0 \\
Office 3 & 43 & 17 & 12 \\
Office 4 & 48 & 2 & 2 \\
Office 5 & 35 & 3 & 3 \\
Office 6 & 65 & 1 & 4 \\
Office 7 & 46 & 0 & 2 \\
Office 8 & 53 & 11 & 8 \\
TOTAL & 372 & 38 & 38 \\
\hline
\end{tabular}
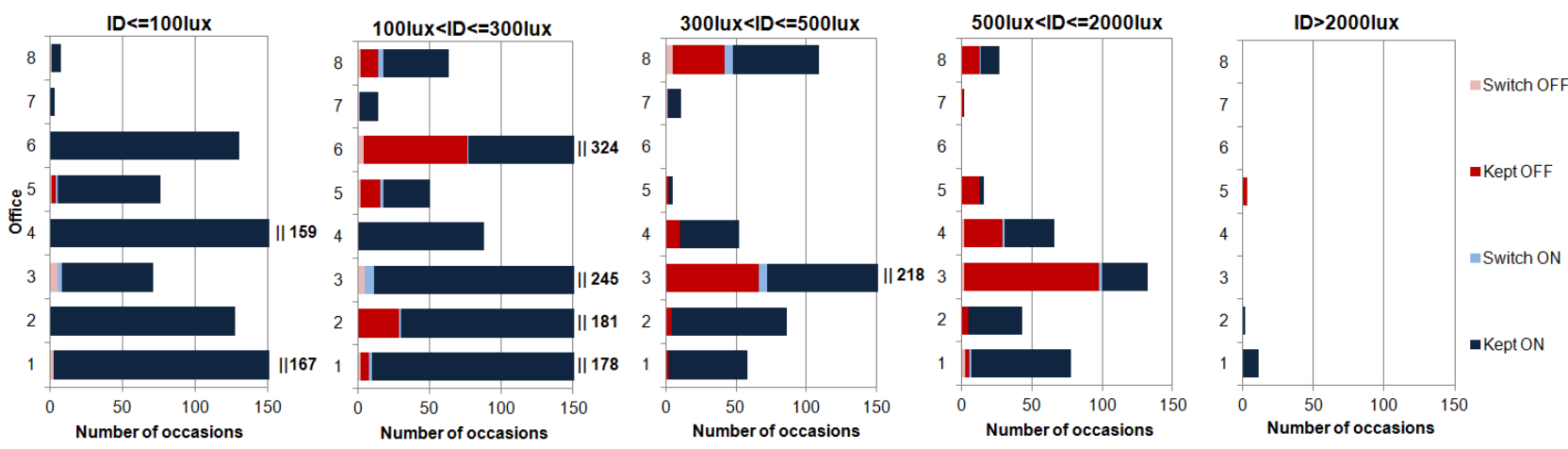

Figure 9: Behaviour of the occupants regarding the electric lighting when remaining continuously in the office (no breaks) as function of the daylight illuminance (ID) - analysis per 20 minute blocks

In summary, the outcomes of the analysis indicate that, for the most part, control patterns for electric lighting of the eight monitored offices were indeed driven by occupation dynamics and also, to some extent, by daylight availability. Specifically:

- Upon arrival, most occupants typically switched electric lighting On. Most of them did that more often when daylight illuminance was low than when it was high, though this was only demonstrated for either particularly low or particularly high daylight illuminance ranges.

- At intermediate periods, the majority of control events occurred just before or just after temporary absences; the decision to switch or keep lights On seems to be significantly influenced by daylight illuminance when entering the room; the number of switch-on or switch-off events not associated to entering or leaving the room was very low.

- Before departure, occupants controlled electric lighting independently daylight illuminance. For an overwhelming majority of departure events, the occupants turned lights Off before leaving.

\subsection{Are daylight illuminance and duration of absence significantly correlated to electric lighting control actions?}

To answer this question, a statistical analysis of the patterns of control the electric lighting in the eight offices was performed. It intended to assess to which extent each of the environmental variables (independent variables in the statistical language) influences the observed results (dependent variable in the statistical language). This was done through a forward logistic regression method, which produces a function that represents the dependent variable as a function of the independent variables that have a statistically significant influence on the value of the dependent variable. The analysis was performed with the SPSS software and the criterion for accepting a variable as statistically significant was set at Sig $<0.05$ (Pallant 2001). 
Published as: P. Correia da Silva, V. Leal, M. Andersen, Occupants interaction with electric lighting and shading systems in real single-occupied offices: Results from a monitoring campaign, Building and Environment, vol. 64, pp. 152-168, 2013 (DOI: http://dx.doi.org/ 10.1016/j.buildenv.2013.03.015)

The first logistic regression, presented in Table 3 in its final calculation form, analyzed the probability that electric lighting being On or Off (dependent variable). The independent variables allowed for the analysis were the daylighting illuminance and the dynamics of occupation (duration of absence before and after period of analysis). For calculation purposes, electric lighting state On assumed a value of "1", while electric lighting state Off took a value of "0". Daylight illuminance and duration of absence were also considered to calculate the probability that electric lighting was either switched On or switched Off for all three types of occupation periods: arrival, intermediate and departure.

Table 3 shows the logistic model that best predicts the state of the electric lighting observed in the eight offices. All the independent variables eligible for analysis (daylighting illuminance, duration of absence before and after period of analysis) we already identified by the model, since their Sig value was lower than 0.05 . However, the resulting model only showed a Nagelkerke's $\mathrm{R}^{2}$ of 0.065 , which indicates a poor relation between prediction model and observations(ref). The overall prediction success is $80.4 \%$, however with extremely discrepant values of $98.8 \%$ for the electric lighting state On and $0.7 \%$ for the electric lighting state Off. The analysis also indicates that all independent variables considered in the model presented were statistically significant (Sig values lower than 0.05 (Pallant 2001)).

Table 3: Logistic regression results for electric lighting state as a function of the daylight availability and duration of absence

\begin{tabular}{|c|c|}
\hline & B $^{\text {a }}$ Sig. \\
\hline Workplane day. Illuminance & $-1.616 \mathrm{E}-3 \mid<0.0005$ \\
Previous duration of absence & $-0.072 \mid 0.015$ \\
Posterior duration of absence & $-0.109 \mid<0.0005$ \\
Constant & $2.042 \mid<0.0005$ \\
\hline Number of observations & $733 \mid 3178$ \\
( "0" | "1") & 3614.399 \\
-2 Log likelihood & 0.040 \\
Cox \& Snell R Square & 0.065 \\
Nagelkerke's R" & $80.4 \%$ \\
Prediction success & $(0.7 \% \mid 98.8 \%)$ \\
("0" |"1") & a logit p = Const. + $\sum$ Bixi \\
\hline \multicolumn{2}{|c|}{} \\
\hline \multicolumn{2}{|c|}{} \\
\hline \multicolumn{2}{|c|}{} \\
\hline
\end{tabular}

Regarding the logistic models that predict electric lighting events - "switch On" and "switch Off" - as a function of the daylight illuminance and duration of absence, the resulting models indicate that:

- On arrival, the most significant variables to statistically predict switch On events are daylight illuminance and posterior duration of absence. Nonetheless, previous duration of absence also proved to be significant for prediction. Logistic model presents a Nagelkerke's $R^{2}$ of 0.329 and an average prediction success of $80.9 \%$;

- At intermediate periods, model of switch On events prediction has a Nagelkerke's $R^{2}$ of 0.148 and a prediction success of $94.0 \%$ (divided by $100 \%$ for the "No events and $0 \%$ for the switch On events). According to the Sig criterion indicated previously ( $\mathrm{Sig}<0.05$ ), from the independent variables selected by the model, only the daylight illuminance proved to be statistically significant, In what regards switch Off events logistic model, a Nagelkerke's $\mathrm{R}^{2}$ of 0.457 indicates a stronger correlation between predictions and observation and a prediction success of $94.8 \%$. For this model, both previous duration of absence and posterior duration of absence were considered statistically relevant for the prediction model;

- On departure, the logistic model shows that only the posterior duration of absence was statistically significant to model switch off events. Neither daylight illuminance nor previous duration of absence were considered by the best-fit selected model. The regression presents a considerably low Nagelkerke's $R^{2}(0.06)$ and a prediction success of $97 \%$, yet driven by the $100 \%$ prediction success of switch off events (against a $0 \%$ of prediction success of "No events").

The results showing the best model for each period is presented in Table 4, considering that observed events got a value of " 1 " while the non existence of events had the value of " 0 ". Probability of switching Off events upon arrival and probability of switching On events upon departure were not calculated due to the low number of events for those particular occupation periods (see section 3.3). 
Published as: P. Correia da Silva, V. Leal, M. Andersen, Occupants interaction with electric lighting and shading systems in real single-occupied offices: Results from a monitoring campaign, Building and Environment, vol. 64, pp. 152-168, 2013 (DOI: http://dx.doi.org/ 10.1016/j.buildenv.2013.03.015)

Table 4: Logistic regression models of electric lighting switching On events and switching Off events, as a function of the daylight availability and duration of absence

\begin{tabular}{|c|c|c|c|c|}
\hline & Arrival & \multicolumn{2}{|c|}{ Intermediate } & Departure \\
\hline & $\begin{array}{l}\text { Switching On events } \\
\qquad \mathrm{B}^{\mathrm{a}} \mid \text { Sig. }\end{array}$ & $\begin{array}{c}\text { Switching On } \\
\text { events } \\
\mathrm{B}^{\mathrm{a}} \mid \text { Sig. }\end{array}$ & $\begin{array}{c}\text { Switching Off } \\
\text { events } \\
B^{\mathrm{a}} \mid \text { Sig. }\end{array}$ & $\begin{array}{l}\text { Switching Off events } \\
\qquad \mathrm{B}^{\mathrm{a}} \mid \text { Sig. }\end{array}$ \\
\hline $\begin{array}{l}\text { Workplane day. } \\
\text { illuminance }\end{array}$ & $-3.489 \mathrm{E}-3 \mid<0.0005$ & $-2.587 E-3 \mid 0.006$ & n.a. ${ }^{b}$ & n.a. ${ }^{b}$ \\
\hline $\begin{array}{l}\text { Previous duration } \\
\text { of absence }\end{array}$ & $0.440 \mid 0.002$ & $-48.210 \mid 0.992$ & $-0.639 \mid 0.007$ & n.a. ${ }^{b}$ \\
\hline $\begin{array}{l}\text { Posterior duration } \\
\text { of absence }\end{array}$ & $-0.429 \mid<0.0005$ & $-48.712 \mid 0.992$ & $3.224 \mid<0.0005$ & $0.588 \mid 0.020$ \\
\hline Constant & $0.251 \mid 0.723$ & $-1.383 \mid<0.0005$ & $-3.757 \mid<0.0005$ & $0.737 \mid 0.526$ \\
\hline $\begin{array}{c}\text { Number of } \\
\text { observations } \\
\text { ("0"| "1") }\end{array}$ & 92 | 258 & 594 | 38 & 2977 | 220 & $8 \mid 257$ \\
\hline -2 Log likelihood & 313.982 & 252.212 & 967.208 & 67.985 \\
\hline $\begin{array}{c}\text { Cox \& Snell R } \\
\text { Square }\end{array}$ & 0.225 & 0.054 & 0.180 & 0.014 \\
\hline Nagelkerke's $\mathbf{R}^{2}$ & 0.329 & 0.148 & 0.457 & 0.060 \\
\hline $\begin{array}{l}\text { Prediction } \\
\text { success } \\
\text { ("0"| "1") }\end{array}$ & $\begin{array}{c}80.6 \% \\
(30.0 \% \mid 95.7 \%)\end{array}$ & $\begin{array}{c}94.0 \% \\
(100 \% \mid 0 \%)\end{array}$ & $\begin{array}{c}94.8 \% \\
(98.6 \% \mid 44.1 \%)\end{array}$ & $\begin{array}{c}97.0 \% \\
(0 \% \mid 100 \%)\end{array}$ \\
\hline
\end{tabular}

\subsection{Do control patterns for shading systems vary considerably with occupation dynamics?}

The experimental data collected during the monitoring period revealed that occupants adjusted the shading system's position less frequently than they adjusted electric lighting (124 shading systems events versus 257 electric lighting events). Following the same approach presented in the previous subsection, results were analyzed according to occupation dynamics - arrival, intermediate and departure periods.

Table 5 indicates the number of shading events for each period of occupation.

Table 5: Summary of shading systems events, according to the occupation dynamics

\begin{tabular}{|c|c|c|c|c|c|c|}
\hline & \multicolumn{2}{|c|}{ Arrival time } & \multicolumn{2}{|c|}{ Intermediate time } & \multicolumn{2}{|c|}{ Departure time } \\
\hline & Closings & Openings & Closings & Openings & Closings & Openings \\
\hline Office 1 & 1 & 34 & 33 & 2 & 24 & 0 \\
\hline Office 2 & 0 & 10 & 14 & 3 & 0 & 1 \\
\hline Office 4 & 1 & 13 & 7 & 2 & 7 & 0 \\
\hline Office 5 & 3 & 0 & 0 & 0 & 0 & 0 \\
\hline Office 6 & 0 & 51 & 20 & 37 & 42 & 0 \\
\hline TOTAL & 5 & 119 & 77 & 45 & 81 & 1 \\
\hline
\end{tabular}

Upon arrival, the most common adjustment was shading opening i.e. an adjustment of the shading position to decrease the percentage of occluded window, which was observed in $34 \%$ of all occupants arrivals .From our observations, it was noted that occupants only occasionally kept the shading deployed after first arriving to the office.

At intermediate periods, results show very different control dynamics for shading depending on the occupant: Offices 1, 2 and 6 presented a very significant number of events (35, 17 and 57 events respectively), whereas occupants of Offices 3 and 4 adjusted shading deployment only in a few occasions, and occupants of Offices 5, 7 and 8 never interact with shading devices at all at intermediate times. Regarding a hypothetical concentration of events on arrival or departure for short absences, Figure 10 presents the percentage of events that were associated to temporary absences (shorter than three hours): results show that $30 \%$ of opening events $\left(n_{\text {TotalEvents }}=45\right)$ and $32 \%$ of closing events $\left(n_{\text {TotalEvents }}=77\right.$ ) were 
Published as: P. Correia da Silva, V. Leal, M. Andersen, Occupants interaction with electric lighting and shading systems in real single-occupied offices: Results from a monitoring campaign, Building and Environment, vol. 64, pp. 152-168, 2013 (DOI: http://dx.doi.org/ 10.1016/j.buildenv.2013.03.015)

related to temporary absences, allowing to conclude that control patterns for shading systems are not primarily driven by occupation dynamics.

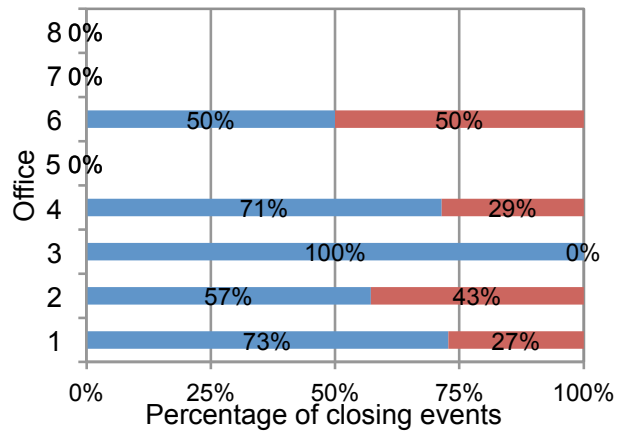

- Closing events not associated with occupant absence Closing events associated with occupant absence

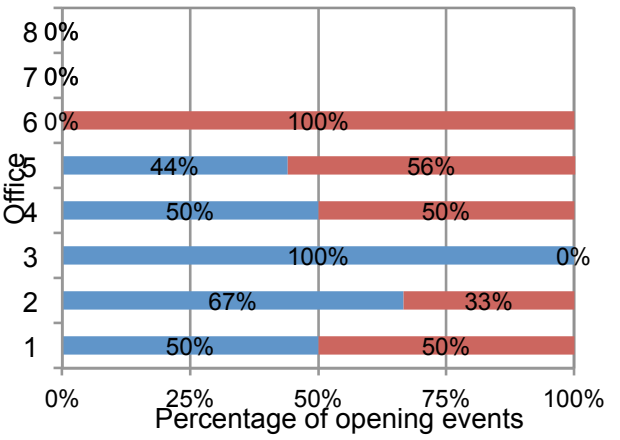

- Opening events not associated with occupant absence

- Opening events associated with occupant absence

Figure 10: Percentage of closing events (a) and opening events (b) associated to occupant absence, during intermediate time (for Office 5 , Office 7 and Office 8 no events were observed)

Results presented in Table 5 indicate that some of the occupants tended to close the shading almost every time they left the office for a long absence - typically the end of the working day - while others rarely or never did, allowing to conclude that control patterns on departures are directly related to occupation dynamics

In summary, results showed that on arrival, occupants frequently opened the shading, and that keeping it deployed on arrival was rare. During intermediate periods, about $70 \%$ of the shading control events were not associated with temporary absences (therefore were independent of occupation dynamics), while at departure times, four of the eight office occupants tended to close the shading when they permanently left the room.

\subsection{Do variations in the transmitted direct solar radiation hitting the workplace influence shading control actions?}

An analysis was made to assess the relation between shading adjustments and direct solar radiation variations when transmitted through the window. Figure 11 shows the proportion of closing and opening events that were related with sudden variations in transmitted direct solar radiation - solar radiation drops of $50 \mathrm{~W} / \mathrm{m}^{2}$ or more for the opening events and solar radiation rises of $50 \mathrm{~W} / \mathrm{m}^{2}$ or more for the closing events. The minimum value of $50 \mathrm{~W} / \mathrm{m}^{2}$ of solar radiation was adopted based on the shading control criterion suggested by Inoue (Inoue, Kawase et al. 1988). Any events associated with absences were excluded from this analysis.

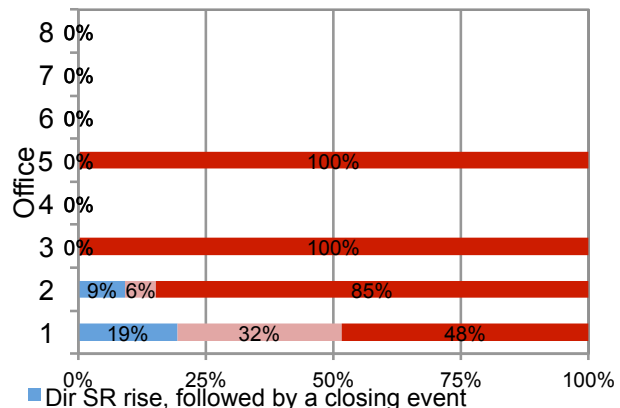

Dir SR rise, when shading was deployed, not followed by a closing event

- Dir SR rise, when shading was not deployed, not (a)

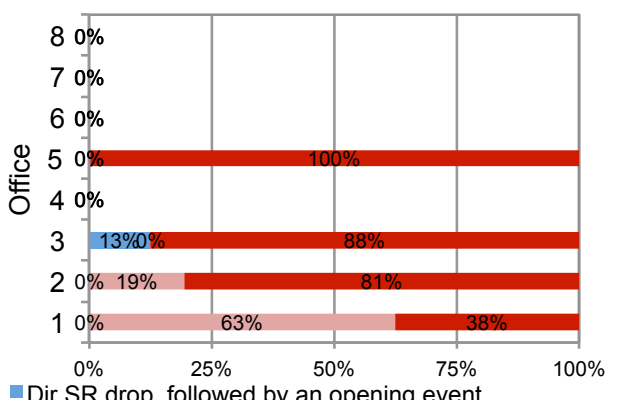

Dir SR drop, followed by an opening event

- Dir SR drop, when shading was deployed, not followed by an opening event

Dir SR drop, when shading was deployed , not followed (b) by an opening event

Figure 11: Percentage of direct solar radiation rises followed by closing events (a) and percentage of direct solar radiation drops followed by opening events (b) during intermediate time.

The left chart shows that a rise in direct solar radiation did not typically drive the occupant to close the shading, even when the shading was not previously in a deployed state (number of direct solar radiation rise occasions: $\mathrm{n}_{\text {office } 1}=31$, $\mathrm{n}_{\text {Office } 2}=33, \mathrm{n}_{\text {Office } 3}=1$ and $\mathrm{n}_{\text {Office }}=3$ ). The right chart shows that in the overwhelming majority of the solar radiation drops these were also not followed by an opening of the shading - in fact only one solar radiation drop followed by an opening event was observed (in Office 3 ) (number of direct solar radiation drop occasions: $n_{\text {Office } 1}=24, n_{\text {Office } 2}=36, n_{\text {Office } 3}=8$ and 
Published as: P. Correia da Silva, V. Leal, M. Andersen, Occupants interaction with electric lighting and shading systems in real single-occupied offices: Results from a monitoring campaign, Building and Environment, vol. 64, pp. 152-168, 2013 (DOI: http://dx.doi.org/ 10.1016/j.buildenv.2013.03.015)

$\mathrm{n}_{\text {Offices }}=7$ ). Thus, the hypothesis that shading adjustments are influenced by variations in transmitted solar radiation was not corroborated at least in the monitored conditions; this finding is further assessed in the two subsequent sections.

\subsection{Which environmental variables are statistically significant for the control of the shading systems?}

A statistical analysis of the shading deployment was performed through a linear multiple forward regression method (Guimarães and Cabral 2007; Devore 2011) using the SPSS software (Pallant 2001). This analysis was conducted using the level of shading deployment level $\left(\mathrm{SD}_{\text {Level }}\right)$ as dependent variable, to ascertain whether the observed environmental variables - daylight workplane illuminance, average window luminance, DGP, DGI, transmitted global solar radiation, transmitted direct solar radiation and ambient temperature - identified by earlier research as important, were indeed influential in this case. The analysis considered simultaneously all eight offices. Table 6 summarizes the elements of the best performing model.

The analysis proved that the independent variables DGP, DGI and vertical direct and global transmitted solar radiation were statistically significant (as revealed by a Sig value $<0.05$ (Pallant 2001)). The other independent variables (workplane daylight illuminance, average window luminance and transmitted direct solar radiation) were not elected by the regression model as statistically significant.

Table 7 shows the Pearson correlation coefficients between each two variables of the model. Results show a strong relationship between average window luminance, DGP and DGI. This was somewhat expected, as a consequence of the definition of DGI and DGP. Transmitted global solar radiation and transmitted direct solar radiation present correlation coefficients higher than 0.90 .

A final statistical model of the shading deployment was computed, not integrating DGI and transmitted direct solar radiation as independent variables, since they are highly correlated with DGP and transmitted direct solar radiation, respectively. The results of this analysis and resulting model are shown in Table 8.

Table 6: Results of the linear multiple regression forward model for shading deployment (independent variable) vs. environmental variables (dependent variables)

\begin{tabular}{|c|c|c|c|c|c|}
\hline Variables & $\mathbf{B}^{\mathrm{a}}$ & Std. error & Beta & $\mathbf{t}$ & Sig. \\
\hline $\begin{array}{c}\text { (Constant) } \\
\text { DGP } \\
\text { Transm. global SR } \\
\text { Transm. direct SR } \\
\text { Workplane daylight illuminance } \\
\text { DGI } \\
\end{array}$ & $\begin{array}{c}0.838 \\
-2.173 \\
2.573-3 \\
-2.219-3 \\
6.431 \mathrm{E}-5 \\
6.172 \mathrm{E}-3 \\
\end{array}$ & $\begin{array}{c}0.022 \\
0.129 \\
1.913 \mathrm{E}-4 \\
1.931 \mathrm{E}-4 \\
1.522 \mathrm{E}- \\
51.467 \mathrm{E}-3 \\
\end{array}$ & $\begin{array}{c}-0.575 \\
1.128 \\
-0.958 \\
0.064 \\
0.144 \\
\end{array}$ & $\begin{array}{c}38.624 \\
-16.859 \\
13.446 \\
-11.490 \\
4.223 \\
4.205 \\
\end{array}$ & $\begin{array}{l}<0.001 \\
<0.001 \\
<0.001 \\
<0.001 \\
<0.001 \\
<0.001\end{array}$ \\
\hline \multicolumn{6}{|c|}{ Adjusted R Square =0.215; Std Error=0.274; F change=17.683; df1=1; df2=4508; Sig. $F$ change= 2.660E-5 } \\
\hline \multicolumn{6}{|c|}{${ }^{a} S_{D_{\text {Level }}}=$ Constant $+\sum B_{i} x_{i}$} \\
\hline
\end{tabular}

Table 7: Pearson correlation coefficients between variables in multiple regression analysis 
Published as: P. Correia da Silva, V. Leal, M. Andersen, Occupants interaction with electric lighting and shading systems in real single-occupied offices: Results from a monitoring campaign, Building and Environment, vol. 64, pp. 152-168, 2013 (DOI: http://dx.doi.org/ 10.1016/j.buildenv.2013.03.015)

\begin{tabular}{ccccccccc}
\hline Variables & $\begin{array}{c}\text { Shading } \\
\text { deploy } \\
\text { ment }\end{array}$ & $\begin{array}{c}\text { Workplan } \\
\text { e daylight } \\
\text { illum. }\end{array}$ & $\begin{array}{c}\text { Ave. win. } \\
\text { luminanc } \\
\mathbf{e}\end{array}$ & DGP & DGI & $\begin{array}{c}\text { Transm. } \\
\text { global } \\
\text { SR }\end{array}$ & $\begin{array}{c}\text { Transm. } \\
\text { direct SR }\end{array}$ & $\begin{array}{c}\text { Ambient } \\
\text { temperat } \\
\text { ure }\end{array}$ \\
\hline $\begin{array}{c}\text { Shading } \\
\text { deployment }\end{array}$ & 1.000 & -0.015 & -0.244 & -0.377 & -0.321 & 0.193 & 0.179 & 0.054 \\
\hline $\begin{array}{c}\text { Workplane } \\
\text { day.illum. }\end{array}$ & -0.015 & 1.000 & 0.509 & 0.377 & 0.375 & 0.282 & 0.245 & -0.027 \\
\hline $\begin{array}{c}\text { Ave. win. } \\
\text { luminance }\end{array}$ & -0.244 & 0.509 & 1.000 & 0.779 & 0.718 & 0.140 & 0.098 & -0.004 \\
\hline DGP & -0.377 & 0.377 & 0.779 & 1.000 & 0.922 & 0.014 & -0.026 & 0.013 \\
\hline DGI & -0.321 & 0.375 & 0.718 & 0.922 & 1.000 & -0.001 & -0.044 & 0.188 \\
\hline $\begin{array}{c}\text { Transm. global } \\
\text { SR }\end{array}$ & 0.193 & 0.282 & 0.140 & 0.014 & -0.001 & 1.000 & 0.986 & 0.051 \\
\hline $\begin{array}{c}\text { Transm. direct } \\
\text { SR }\end{array}$ & 0.179 & 0.245 & 0.098 & -0.026 & -0.044 & 0.986 & 1.000 & 0.040 \\
\hline $\begin{array}{c}\text { Ambient } \\
\text { temperature }\end{array}$ & 0.054 & 0.027 & 0.004 & 0.013 & 0.188 & 0.051 & 0.040 & 1.000 \\
\hline Table 8 & & & & & & & &
\end{tabular}

Table 8: Final results of the multiple regression forward model for shading deployment (independent variable) vs. environmental variables (dependent variables)

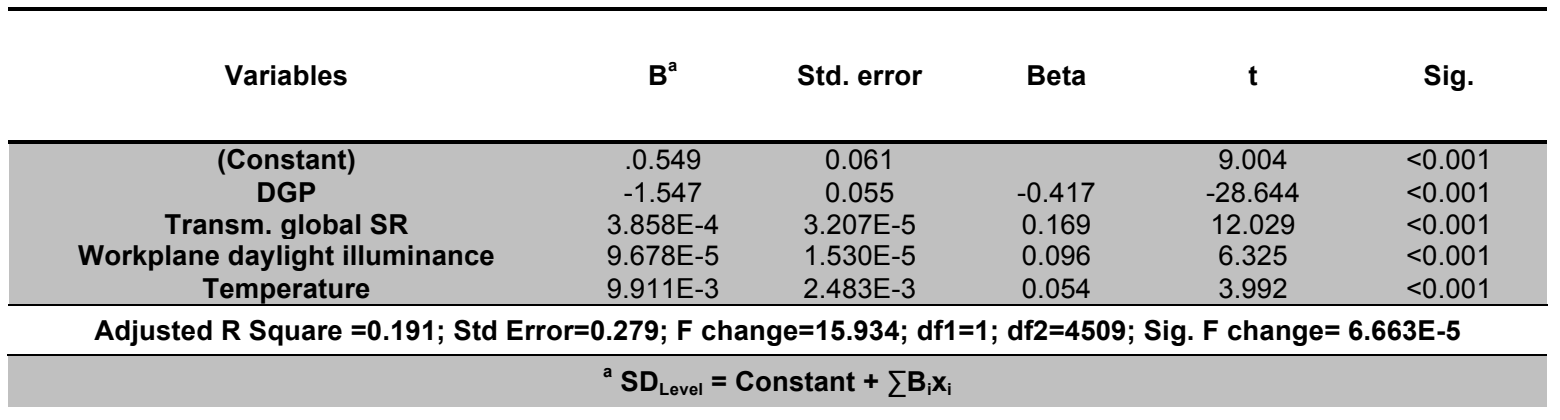

A statistical analysis of the shading events (shading deployment adjustments) was also performed, based on logistic regressions.. This analysis estimated the probability that shading is adjusted, either opened or closed, as a function of environmental conditions and dynamics of occupation (duration of absence - before the event and after the event). It was defined that, for each observation time-step, a shading event takes a value of " 1 ", while the non existence of an event takes a value of " 0 ". Separated analysis were made for the arrival, intermediate and departure times. No regression analysis was made for closing events at arrival time nor for opening events at departure time, since the number of events is negligible (see Table 5). Table 9 indicates the logistic regression coefficients for each predictor variable and performance tests for the models of opening (arrival and intermediate time) and closing events (intermediate and departure time).

The logistic regression focused on arrival time indicates a Nagelkerke's $R^{2}$ of 0.681 , which shows a strong relationship between model prediction and observations. The overall prediction success is significantly high averaging $88.9 \%(92.1 \%$ for the "No events" and $82.4 \%$ for the "Events"). Workplane daylight illuminance, average window luminance, DGP, DGI, vertical transmitted global solar radiation and ambient temperature make a statistically significant contribution to prediction, since they all present significance values lower than 0.05 (Pallant 2001).

At intermediate time, logistic models present a considerably low Nagelkerke's $R^{2}(0.228$ and 0.179 for opening and closing events, respectively), which shows a weak relationship between model prediction and observations The most significant variables to opening events prediction are the workplane daylight illuminance, average window luminance, DGI, ambient temperature and previous duration of absence. For the closing events predictions, significant variables are reduced to DGP, vertical global transmitted solar radiation, ambient temperature and previous duration of absence. The resulting logistic models are incapable of predicting opening or closing "Events", even if they are particularly accurate for the "No Events" (100\% of success), The low accuracy of the models for predicting "Events" justifies an alternative approach for the analysis of the observations, which is presented in next sections.

In what regards the closing events prediction at departure time, the low value of Nagelkerke's $R^{2}$ of 0.170 indicates that predicted events are poorly related to environment variables. From these, only workplane daylight illuminance, vertical 
Published as: P. Correia da Silva, V. Leal, M. Andersen, Occupants interaction with electric lighting and shading systems in real single-occupied offices: Results from a monitoring campaign, Building and Environment, vol. 64, pp. 152-168, 2013 (DOI: http://dx.doi.org/ 10.1016/j.buildenv.2013.03.015)

transmitted direct solar radiation and ambient temperature were statistically significant for the prediction model. This logistic model has an average $75.7 \%$ prediction success, however unevenly split between $97.6 \%$ for the "No Events" and only $8.6 \%$ for the "Events".

Table 9: Logistic regression models of shading opening events and closing events, as a function of the environmental variables and duration of absence

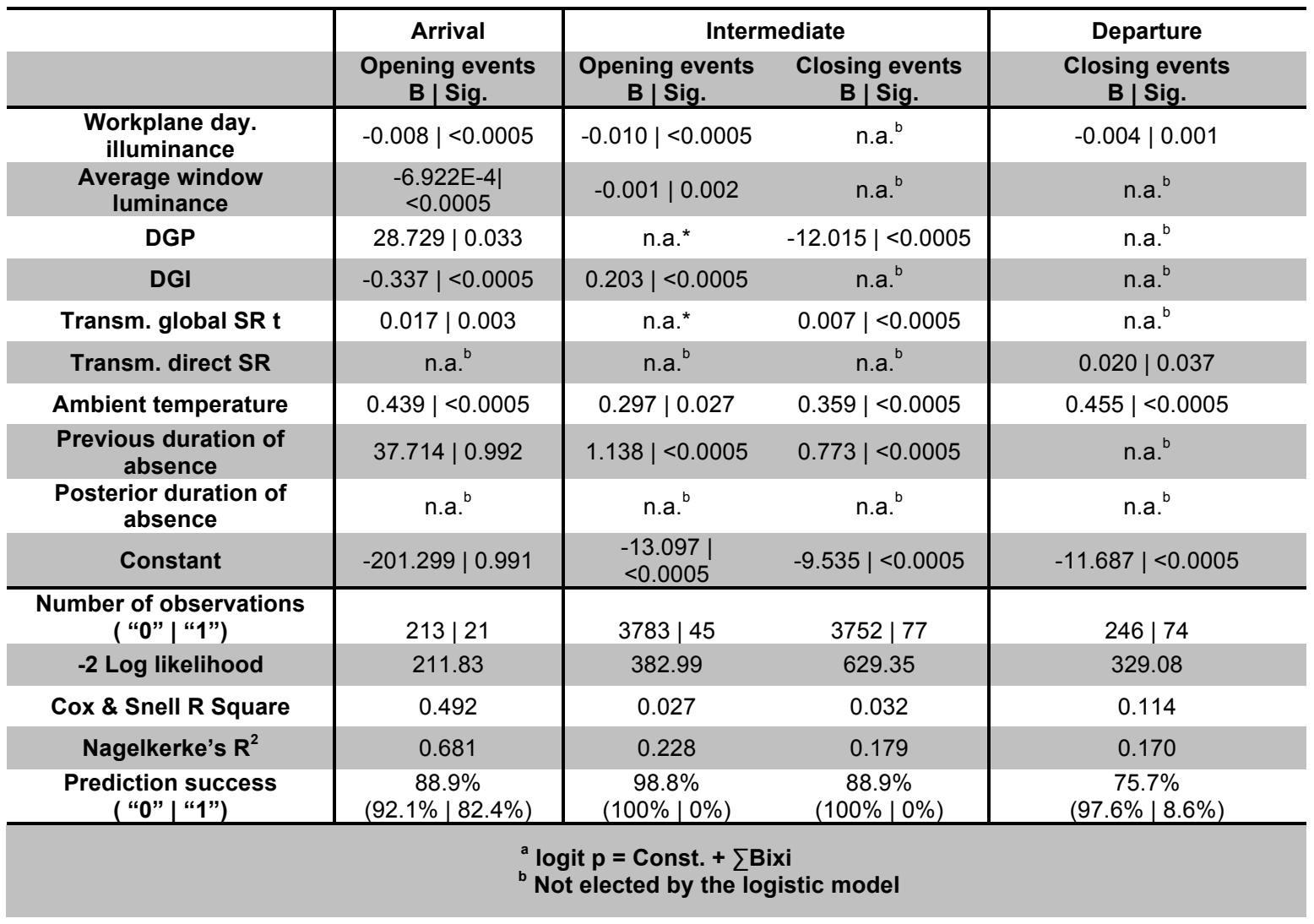

\subsection{Do the observed shading states agree with those suggested by previously published shading control patterns?}

The identification of previously published control patterns (Correia da Silva, Leal et al. 2012) allowed a comparison between observed shading states and expected states according to those control patterns. For the purpose of this study, only deterministic control patterns were considered, whose variables and thresholds are summarized in Table 10. Deterministic control patterns consider that shading is deployed whenever the control variables exceed the associated threshold values, and not deployed otherwise.

Table 10: Control patterns the shading systems found in the literature

\begin{tabular}{|c|c|c|c|c|c|c|c|}
\hline Control pattern & 1 & 2 & 3 & 4 & 5 & 6 & 7 \\
\hline Author & $\begin{array}{l}\text { (Roche, } \\
\text { Dewey et } \\
\text { al. 2000; } \\
\text { Roche } \\
\text { 2002) }\end{array}$ & $\begin{array}{l}\text { (Sutter, } \\
\text { Dumortier et } \\
\text { al. 2006) }\end{array}$ & $\begin{array}{l}\text { (Lee and } \\
\text { Selkowitz } \\
\text { 1995) }\end{array}$ & $\begin{array}{c}\text { (Wienold and } \\
\text { Christoffersen } \\
2006 ; \\
\text { Wienold } \\
\text { 2009) }\end{array}$ & $\begin{array}{l}\text { (Lee and } \\
\text { Selkowitz } \\
\text { 1995) }\end{array}$ & $\begin{array}{l}\text { (Inoue, } \\
\text { Kawase et } \\
\text { al. 1988) }\end{array}$ & $\begin{array}{c}\text { (Foster } \\
\text { and } \\
\text { Oreszczyn } \\
2001 ; \\
\text { CEN } \\
2008)\end{array}$ \\
\hline Variable & $\begin{array}{l}\text { Workplane } \\
\text { Illuminance }\end{array}$ & $\begin{array}{l}\text { Average } \\
\text { window } \\
\text { luminance }\end{array}$ & DGI & DGP & $\begin{array}{l}\text { Vertical } \\
\text { transmitted } \\
\text { direct solar } \\
\text { radiation }\end{array}$ & $\begin{array}{l}\text { Vertical } \\
\text { transmitted } \\
\text { direct solar } \\
\text { radiation }\end{array}$ & $\begin{array}{l}\text { Vertical } \\
\text { incident } \\
\text { global } \\
\text { solar } \\
\text { radiation }\end{array}$ \\
\hline Threshold & 1800 lux & $1800 \mathrm{~cd} / \mathrm{m}^{2}$ & 20 & $40 \%$ & $94.5 \mathrm{~W} / \mathrm{m}^{2}$ & $50 \mathrm{~W} / \mathrm{m}^{2}$ & $300 \mathrm{~W} / \mathrm{m}^{2}$ \\
\hline
\end{tabular}

Figure 12 shows the shading deployment as a function of the threshold values of seven control patterns indicated in 
Published as: P. Correia da Silva, V. Leal, M. Andersen, Occupants interaction with electric lighting and shading systems in real single-occupied offices: Results from a monitoring campaign, Building and Environment, vol. 64, pp. 152-168, 2013 (DOI: http://dx.doi.org/ 10.1016/j.buildenv.2013.03.015)

Table 5. For the purpose of this research, the minimum value of shading deployment of $65 \%$ was adopted to consider the shading as "deployed".

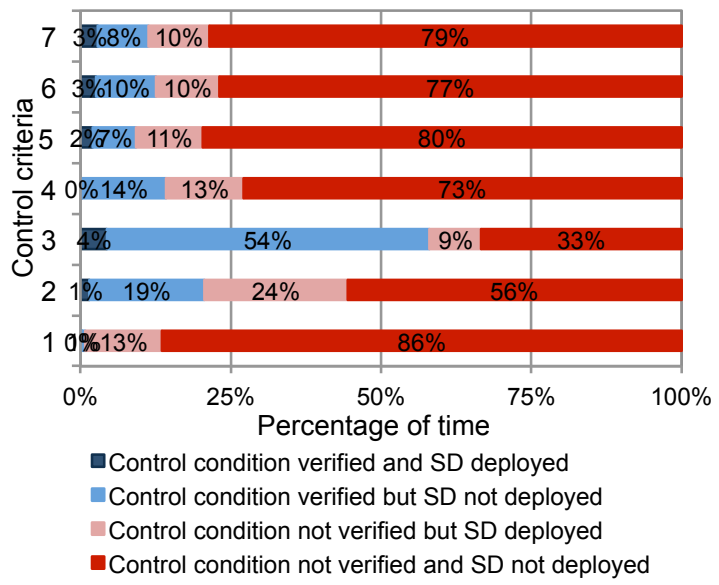

Figure 12: Percentage of time where control patterns were (or were not) verified (average of all eight offices)

Overall, from Figure 12 it is found that shading is only rarely deployed (percentage of time that shading is deployed: $M=0.14$, S.D. $=0.35$ and $n=4514$ ) but also that the control conditions - for which predicted thresholds would be exceeded were actually not verified (the exception being control pattern 3, based on DGI). In that sense, published patterns apparently work well in predicting when shadings would not be deployed; however, most of the times where shading was deployed, control conditions were also not verified, and most of the times where the control conditions were verified, the shading was not deployed. This finding questions the applicability of the published patterns to predict discomfort and shading control actions, at least for the offices and occupation profiles at hand here.

\subsection{Do observed control events occur as predicted by the control conditions for shading states?}

The previous section reviewed a number of criteria previously published, which intend to predict the state of shading devices based on the value of a given environmental variable (control condition). Those criteria are also considered in this section, but now with the goal of investigating if the observed control events occurred when the control condition according to Table 10 was observed or not. Figure 14 shows the percentages of events (opening and closing) that actually occurred according to those control conditions.

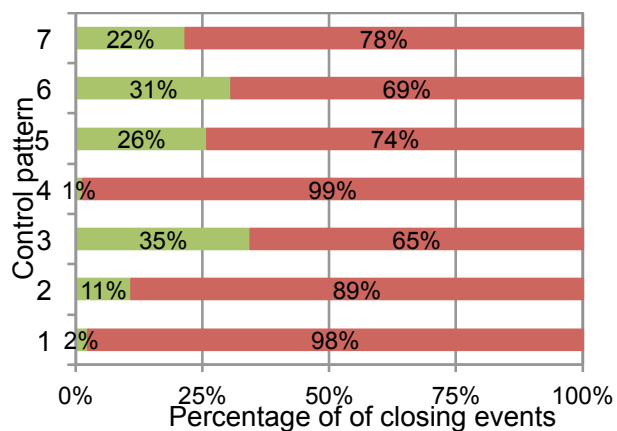

Closing events with closing control condition verified

(a) Closing events with closing control condition not verified

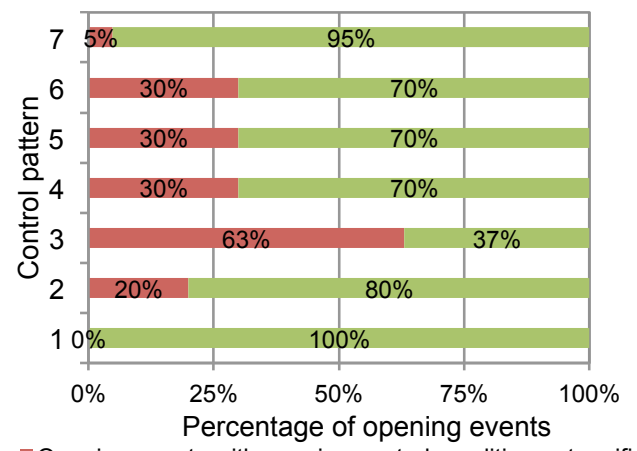

- Opening events with opening control condition not verified

(b) Opening events with opening control condition verified

Figure 13: Percentage of closing (a) and opening (b) events (average of the eight offices) that took place when the control conditions of each pattern was (or was not) verified, at intermediate periods

These results indicate that only $18 \%$ of the closing events $\left(n_{\text {Totalevents }}=77\right)$ of the eight offices occur according to the control patterns (i.e. when the closing control condition is verified). The control pattern with better correspondence to observations is the number $3(\mathrm{DGI}>20)$, which nevertheless does not pass an agreement of $35 \%$. For opening events $\left(n_{\text {TotalEvents }}=45\right)$,results show a much better correspondence between pattern predictions and observations, with patterns number 1 (illuminance $<1800 \mathrm{lux}$ ) and 7 (solar radiation $<300 \mathrm{~W} / \mathrm{m}^{2}$ ) having the best correspondences with observations. The probability that occupants perform control actions as a function of environmental conditions has been addressed in previously published studies (Inkarojrit 2005; Haldi and Robinson 2009). The correlation between observations derived 
Published as: P. Correia da Silva, V. Leal, M. Andersen, Occupants interaction with electric lighting and shading systems in real single-occupied offices: Results from a monitoring campaign, Building and Environment, vol. 64, pp. 152-168, 2013 (DOI: http://dx.doi.org/ 10.1016/j.buildenv.2013.03.015)

from the present monitoring campaign and those other patterns will, due to its volume and complexity, be presented in a separate paper.

\subsection{Which share of shading control actions are simultaneous with lighting control actions?}

The analysis of the observed occupants' behavior suggests that some occupants follow patterns that combine electric lighting adjustments with shading deployment adjustments. Figure 14 shows the percentage of events, in each of the eight offices, that were combined events (shading control actions simultaneous with lighting control actions) while Table 11 indicates the percentage of electric lighting events that occurred simultaneously with shading actions.

On arrival, a total of 161 combined events of a total of 381 events were observed. Combined events (switching lights on and opening shading) of Offices 1 and 6 are more frequent than isolated events (Office 1: 34 combined events versus 8 isolated events; Office 6: 51 combined events versus 2 isolated events), being observed that more than $80 \%$ of the observed events of Offices 1 and 6 on arrivals were combined.

During intermediate periods, a minor number of combined events was observed (62 combined events of a total of 554 events). From all the offices monitored, Office 6 presented a much higher percentage of combined events, revealing that control patterns of Office 6's occupant were based on simultaneous control of shadings and electric lighting (54 combined events of a total of 140 events).

At departure times, observations presented consistent control patterns: electric lighting was switched off (72 combined events of a total of 261 events) and shadings were closed (71 combined events of a total of 81 events).
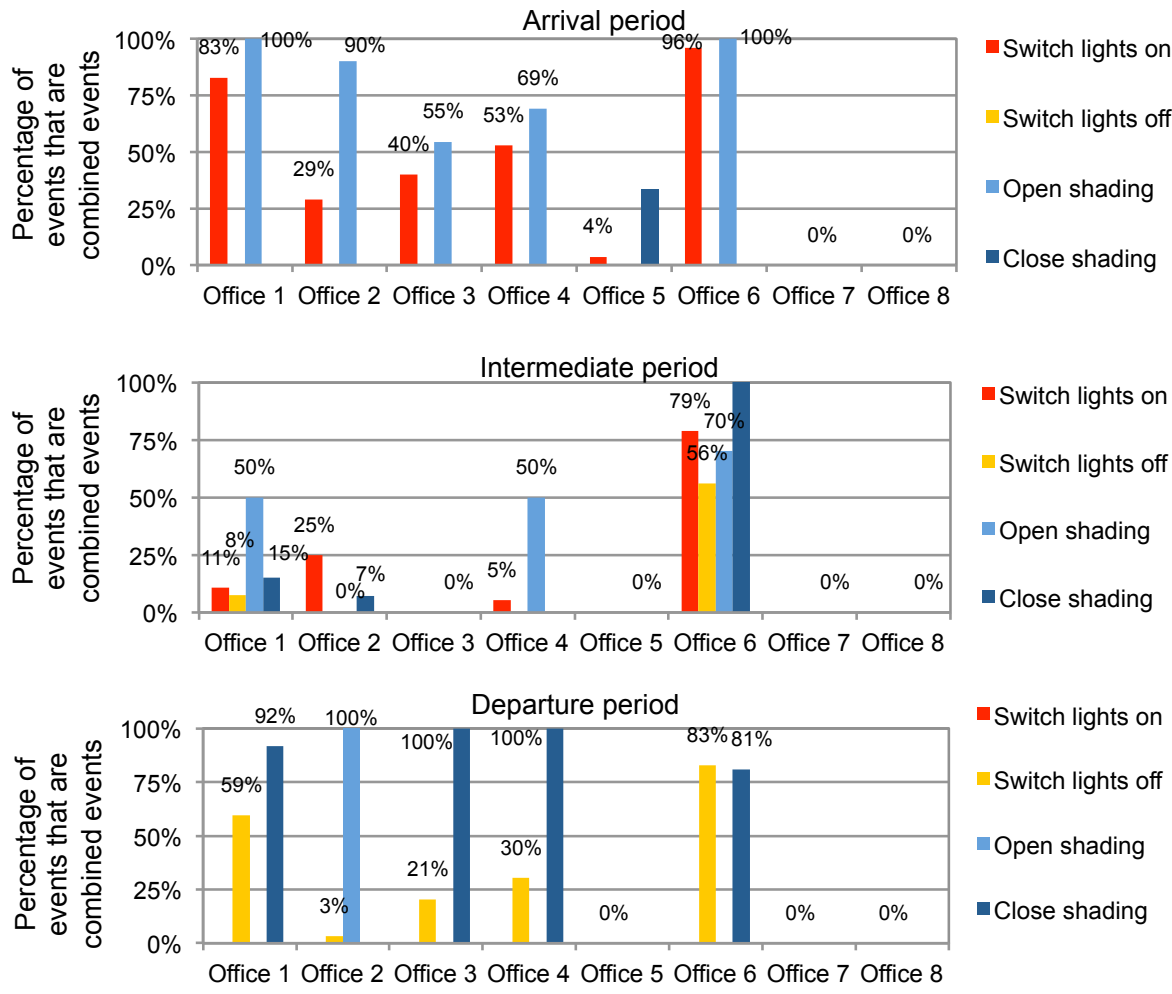

Figure 14: Percentage of combined events for all eight offices

Overall, the analysis revealed that, for most of the occupants, combined lighting and shading control events prevail at the arrival and departure times, while for intermediate periods, non-combined control events prevail. 
Published as: P. Correia da Silva, V. Leal, M. Andersen, Occupants interaction with electric lighting and shading systems in real single-occupied offices: Results from a monitoring campaign, Building and Environment, vol. 64, pp. 152-168, 2013 (DOI: http://dx.doi.org/ 10.1016/j.buildenv.2013.03.015)

Table 11: Distribution of the electric lighting events (switch On and switch Off) according to the actions on shading systems (C - Close; NoA - No Action; O - Open) in the same 20 minutes blocks

\begin{tabular}{|c|c|c|c|c|c|c|c|c|c|c|c|c|}
\hline & \multirow{2}{*}{\multicolumn{3}{|c|}{$\begin{array}{l}\text { Arrival time } \\
\text { Switch On }\end{array}$}} & \multicolumn{6}{|c|}{ Intermediate time } & \multirow{2}{*}{\multicolumn{3}{|c|}{$\frac{\text { Departure time }}{\text { Switch Off }}$}} \\
\hline & & & & \multicolumn{3}{|c|}{ Switch On } & \multicolumn{3}{|c|}{ Switch Off } & & & \\
\hline & C & NoA & 0 & C & NoA & 0 & C & NoA & 0 & C & NoA & 0 \\
\hline Office 1 & $0 \%$ & $17 \%$ & $83 \%$ & $11 \%$ & $89 \%$ & $0 \%$ & $5 \%$ & $93 \%$ & $3 \%$ & $0 \%$ & $100 \%$ & $0 \%$ \\
\hline Office 2 & $0 \%$ & $71 \%$ & $29 \%$ & $25 \%$ & $75 \%$ & $0 \%$ & $0 \%$ & $100 \%$ & $0 \%$ & $0 \%$ & $97 \%$ & $3 \%$ \\
\hline Office 3 & $0 \%$ & $60 \%$ & $40 \%$ & $0 \%$ & $100 \%$ & $0 \%$ & $0 \%$ & $100 \%$ & $0 \%$ & $21 \%$ & $79 \%$ & $0 \%$ \\
\hline Office 4 & $0 \%$ & $47 \%$ & $53 \%$ & $0 \%$ & $95 \%$ & $5 \%$ & $0 \%$ & $100 \%$ & $0 \%$ & $30 \%$ & $70 \%$ & $0 \%$ \\
\hline Office 5 & $4 \%$ & $96 \%$ & $0 \%$ & $0 \%$ & $100 \%$ & $0 \%$ & $0 \%$ & $100 \%$ & $0 \%$ & $0 \%$ & $100 \%$ & $0 \%$ \\
\hline Office 6 & $0 \%$ & $4 \%$ & $96 \%$ & $3 \%$ & $21 \%$ & $76 \%$ & $54 \%$ & $44 \%$ & $2 \%$ & $83 \%$ & $17 \%$ & $0 \%$ \\
\hline Office 7 & $0 \%$ & $100 \%$ & $0 \%$ & $0 \%$ & $100 \%$ & $0 \%$ & $0 \%$ & $100 \%$ & $0 \%$ & $0 \%$ & $100 \%$ & $0 \%$ \\
\hline Office 8 & $0 \%$ & $100 \%$ & $0 \%$ & $0 \%$ & $100 \%$ & $0 \%$ & $0 \%$ & $100 \%$ & $0 \%$ & $0 \%$ & $100 \%$ & $0 \%$ \\
\hline TOTAL & $0 \%$ & $58 \%$ & $42 \%$ & $2 \%$ & $86 \%$ & $12 \%$ & $13 \%$ & $86 \%$ & $1 \%$ & $19 \%$ & $81 \%$ & $0 \%$ \\
\hline
\end{tabular}

\subsection{How do observed control patterns compare with behavioral models found in the literature?}

The occupants' control patterns observed during the monitoring campaign were compared to four of the most cited behavioral models indicated in the literature: two related to the control of the electric lighting - Switch On probability (Hunt 1979) and Switch Off probability (Pigg, Eilers et al. 1996) - and two related to the control of the shading systems opening/closing shading algorithm (Haldi and Robinson 2009) and closing probability (Inkarojrit 2008). The predicted probability for an action (computed based on environmental conditions) was compared against the frequency with which such adjustment was observed during monitoring. In the case of the level of shading deployment, the predicted shading systems state was compared with the observed shading deployment (SD).

The Hunt criterion indicates the probability of switching electric lighting On, based on daylight illuminance levels experienced by occupants when first arriving in the day. Figure 15 shows the probabilities computed for the range of daylight illuminances observed in monitored offices (red line). The frequencies with which occupants actually switched electric lighting on when first arriving in the day during the monitoring campaign are also represented in the figure (light grey dots). These were calculated individually for each of the eight offices, considering illuminance bins according to the range of daylight illuminances, varying from 50 lux bins in the bottom-end to 100 lux bins in the higher end, according to the density of measurements fallings on each range. A logistic regression for the switch on frequency was also computed and represented in Figure 15, considering the data of the eight offices altogether.

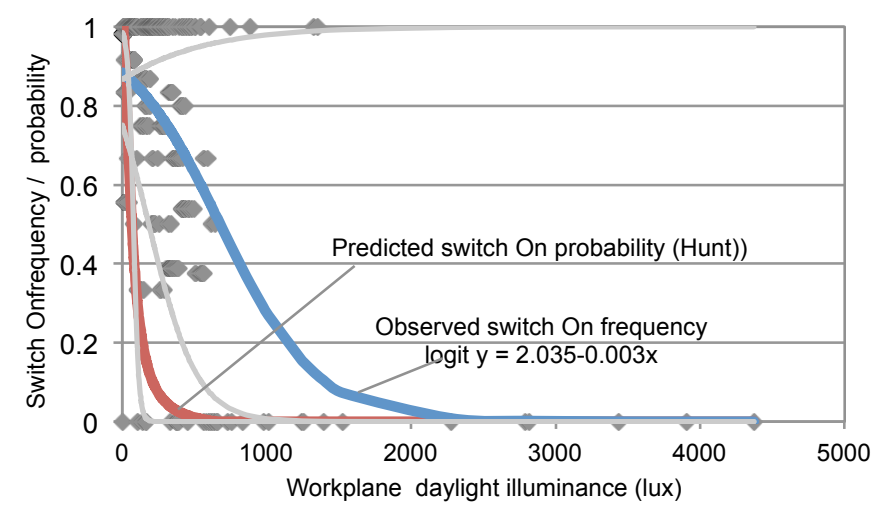

Figure 15: Observed Switch On frequency of the eight offices compared to the Switch On probability according to the Hunt criterion, both for the time of arrival. Grey dots represent observed switch on frequencies for each of the eight offices. Light lines represent the observed Switch On logit regressions for the three offices in which the regression produced results

The analysis of Switch On frequencies showed that occupants controlled electric lighting state in many of the arrival events, with a particularly high frequency of Switch On events for electric lighting when daylight illuminance (DI) was lower than 200 lux (frequency superior to $80 \%$ ). For daylight illuminances up to 1000 lux, there were also several Switch On 
Published as: P. Correia da Silva, V. Leal, M. Andersen, Occupants interaction with electric lighting and shading systems in real single-occupied offices: Results from a monitoring campaign, Building and Environment, vol. 64, pp. 152-168, 2013 (DOI: http://dx.doi.org/ 10.1016/j.buildenv.2013.03.015)

frequencies superior to $30 \%$. The derived trends indicate a switch on frequency of $75 \%$ for DI of 300 lux and of $50 \%$ for DI of 670 lux (Figure 15). The observed Switch On frequency is found to be similar to the Switch On probabilities suggested by Hunt for the high illuminances, but very different for low illuminances. It is thus concluded that, at arrival time, occupants of the monitored offices were considerably more active and less sensitive to DI than the Hunt probability would predict.

The Pigg probability model (Pigg, Eilers et al. 1996) suggests that the major drivers for switching electric lighting Off are the act of leaving the office and the expected absence time, and correlates the probability of electric lighting being switched Off with the duration of absence. Figure 16 shows the Switch Off probabilities according to this criterion, and compares them to the observed Switch Off frequencies for each of the eight monitored offices and the resulting average Switch Off frequency for the comprehensive dataset.

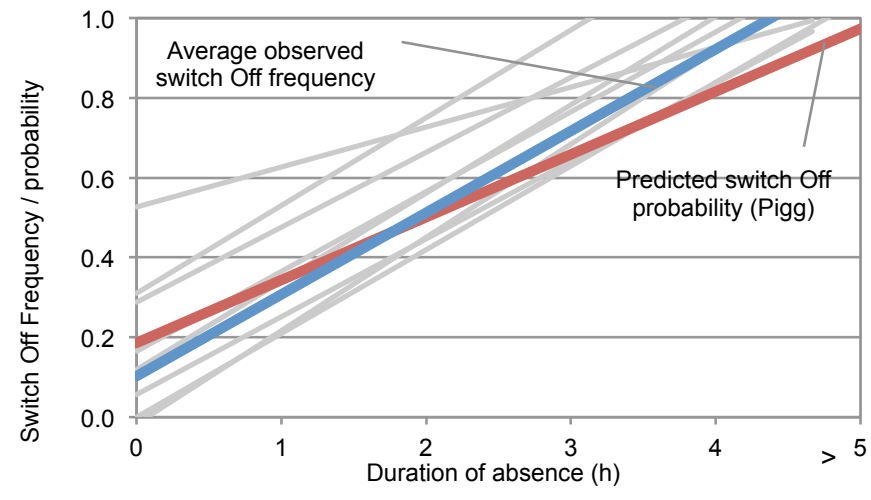

Figure 16: Observed switch off frequency and predicted switch off probability according to Pigg criterion. Light lines represent observed switch off frequencies of each of the eight offices.

Among the eight offices, significant differences are revealed in terms of observed Switch Off frequencies, represented with light lines in Figure 16. However, results show a clear correlation between the duration of absences and the electric lighting Switch Offs. Generally, the comparison of observed average frequency and Pigg probability shows good agreement, both in the qualitative pattern of control and in the quantitative frequency and probability comparison. Consequently, the adequacy of Pigg probability to predict occupants' behavior is confirmed by the present observations.

Regarding the closure of shading systems at a time of the first arrival in the day, Inkarojrit points out that the probability, depends on the visual environment conditions faced by occupants when entering-the office. Figures 17-20 show the closing probability computed through Inkarojrit's models compares it to the observed closing frequency as a function of, respectively, average window luminance, maximum window luminance, background luminance and transmitted global solar radiation registered in the monitored offices at arrival time.

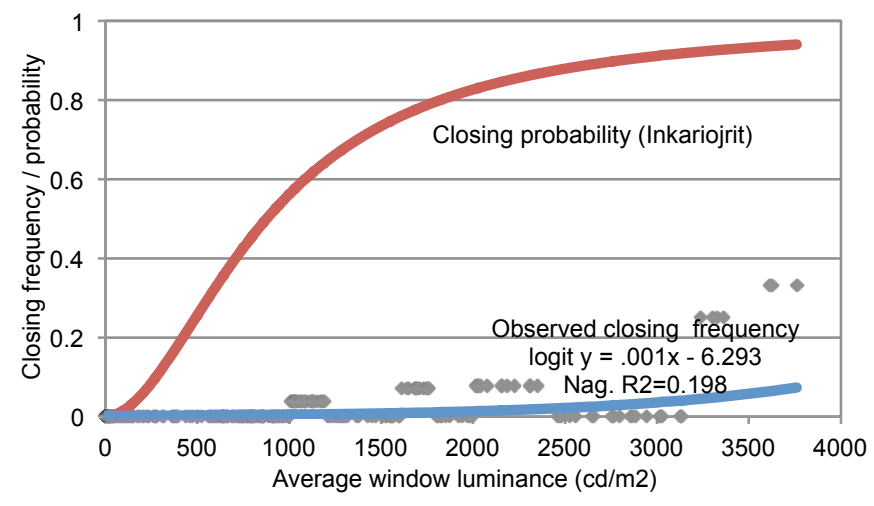

Figure 17: Closing probability according to Inkarojrit criterion and observed closing frequency as function of the average window luminance. Grey dots represent observed closing frequencies for each of the eight offices. 
Published as: P. Correia da Silva, V. Leal, M. Andersen, Occupants interaction with electric lighting and shading systems in real single-occupied offices: Results from a monitoring campaign, Building and Environment, vol. 64, pp. 152-168, 2013 (DOI: http://dx.doi.org/ 10.1016/j.buildenv.2013.03.015)

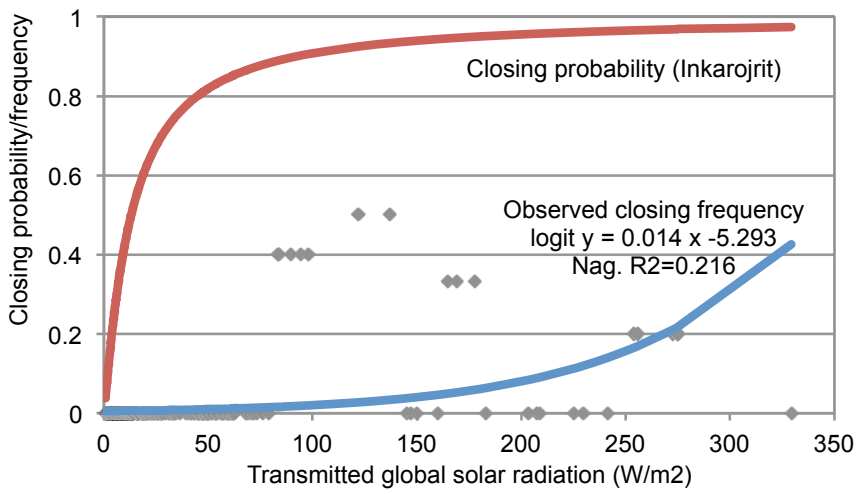

Figure 18: Closing probability according to Inkarojrit criterion and observed closing frequency as function of the transmitted global solar radiation. Grey dots represent observed closing frequencies for each of the eight offices.

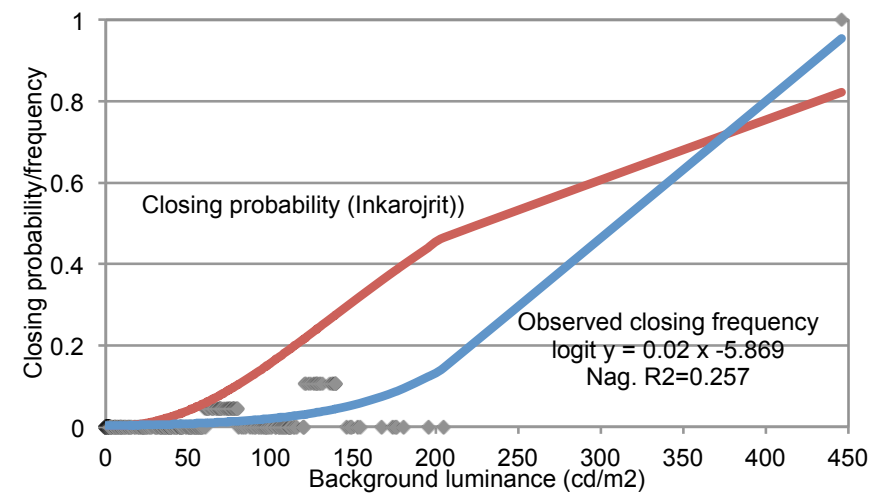

Figure 19: Closing probability according to Inkarojrit criterion and observed closing frequency as function of the background luminance. Grey dots represent observed closing frequencies for each of the eight offices.

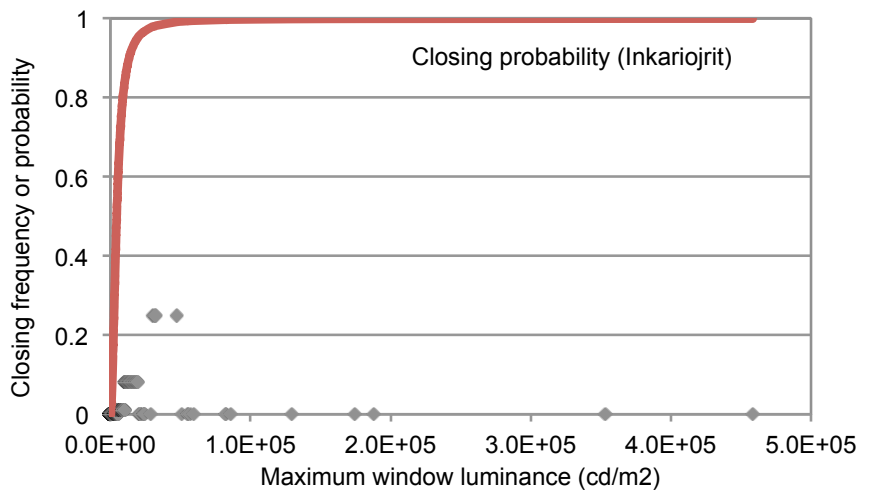

Figure 20: Closing probability according to Inkarojrit criterion and observed closing frequency as function of the maximum window luminance. Grey dots represent observed closing frequencies for each of the eight offices

During the monitoring campaign, occupants closed shading systems at arrival time in only rare occasions, as presented in section 3.5. As a result, the frequency with which the shading systems were closed is very low. Indeed, the comparison of Inkarojrit criteria with observation of occupants behavior shows that observed closing frequencies based on window average luminance and transmitted global solar radiation are much lower than predicted closing probabilities for the full range of environmental conditions, hence not confirming their validity to predict observed occupants behavior. In what regards the closing probability based on background luminance (Figure 19), a reasonable qualitative similarity between predictions and observations is found. No regression function could be computed to account for window maximum luminance because of the large luminance range and low number of observed closing actions.

Regarding shading control, the Haldi algorithm (Haldi and Robinson 2009) first determines which shading control action is most likely (closing or opening) to happen as a function of the indoor illuminance levels. After that, a Monte Carlo method is resorted to determine whether the most probable action actually occurs or not in a given time step. Table 12 
Published as: P. Correia da Silva, V. Leal, M. Andersen, Occupants interaction with electric lighting and shading systems in real single-occupied offices: Results from a monitoring campaign, Building and Environment, vol. 64, pp. 152-168, 2013 (DOI: http://dx.doi.org/ 10.1016/j.buildenv.2013.03.015)

summarizes, for arrival and intermediate periods, the number of predicted versus observed control actions for the full dataset (all eight offices).

Table 12: Comparison of the number of control actions predicted by Haldi criteria with the observed ones

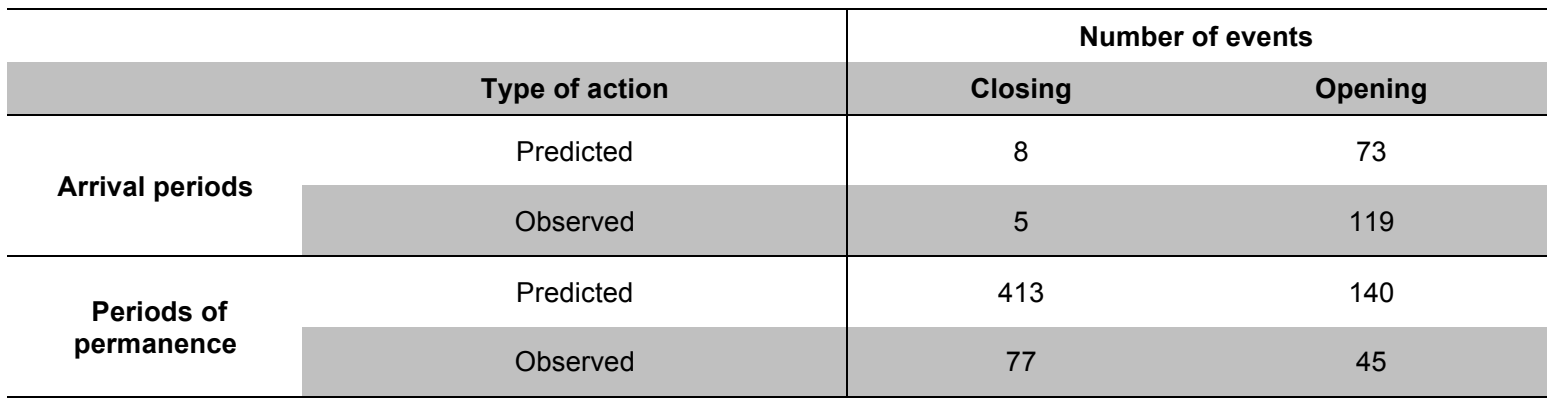

For the conditions that were indeed observed during the arrival periods, we find that the Haldi criteria would indicate that shading openings were the most likely actions. Observed occupants behavior indeed confirms this, showing that opening actions were preferable over closing events. In quantitative terms, the predictions also correlated quite well with observations (same orders of magnitude), despite some differences in the actual numbers: the model typically underpredicted the number of opening actions and over-predicted the number of closing actions. For periods of prolonged office occupation, the observations also confirmed Haldi's model prediction that there would be more closings than openings. On the other hand, there were significant quantitative differences between predictions and observations, with a clear overprediction of both openings and closures.

Overall, the analysis of the observations vs. model predictions revealed a good agreement for the Pigg model for control of the electric lighting (switch off) before departures, and validated the relevance of the duration of absence to electric lighting Switch Offs controls. Additionally, results agreed qualitatively but not quantitatively on the Hunt model for the switch on of electric lighting upon arrivals, and on Haldi's model for control (opening or closing), of the shading systems. They were in neither qualitative nor quantitative agreement with Inkarojrit's model for shading closing actions when occupants arrive to the office.

\section{CONCLUSIONS}

This study presents a contribution to the characterization of occupants' behavior regarding the manual control of electric lighting and shading devices in offices with only one occupant and under normal operation. It describes the procedure and results of a monitoring campaign of eight single-occupied office rooms for time periods ranging from 35 to 65 days, performed in Porto, Portugal, between December 2010 and July 2011.

As far as electric lighting control is concerned, the first important finding was that most controls $(91 \%$ of the total observed) occurred just after the occupant arrived in the room or just before (s)he left, be it long absences (inter-day) or short (intra-day). A second important finding was that for most occupants, the decision to turn lights on when arriving was dependent on the daylight level in the room at that moment since, in average, occupants switched electric lighting On more frequently for the lower daylight illuminances. For temporary absences, the decision to turn lights On upon return was considerably higher when the daylight level was lower than 500 lux than when it was higher. There were however two of the eight occupants whose behavior seemed to be independent of the environmental conditions on arrival.

In terms of shadings control, it was observed that most of the opening events occurred at the moment of first arrival in the day, and that most of the closing events occurred at the moment of departure at the end of the day. However, there was also a reasonable number $(37 \%)$, of opening and closing events that occurred during intermediate periods, from which most $(65 \%)$. were not associated with leaving or returning to the room. The analysis of the occasions with variations of the direct solar radiation transmitted through the window showed that occupants were not significantly driven to control shadings based on sudden variations of solar radiation. 
Published as: P. Correia da Silva, V. Leal, M. Andersen, Occupants interaction with electric lighting and shading systems in real single-occupied offices: Results from a monitoring campaign, Building and Environment, vol. 64, pp. 152-168, 2013 (DOI: http://dx.doi.org/ 10.1016/j.buildenv.2013.03.015)

A linear multiple regression of the measurements showed that daylight workplane illuminance, DGP, DGI and transmitted solar radiation were the most robust environmental variables able to predict shading deployment patterns. Furthermore, the logistic regressions to estimate shading events probability showed a poor agreement to predict occupants' shading adjustment actions, regardless of the overall good agreement between predictions and observations, since this was mostly based on correctly prediction lack of action.

Results also allowed to conclude that the patterns observed for the control of shading systems were not correlated to those inferred from the literature regarding the prediction of the shading states (as observed in section 3.7). It was found that while there is a reasonably good agreement in predicting the open (not deployed) states, poor agreement was found regarding the prediction of the closed (deployed) state: often when the control condition to close was verified were the shadings still kept in a opened state; concomitantly, it was found that most of the opening and closing events occurred while the respective control conditions were not verified.

Another interesting result was that control patterns of five of the eight occupants were consistently combined (i.e. almost simultaneous) actions, involving both electric lighting and shading deployment. Such combined events were observed especially at arrival and departure times.

Regarding the comparison of the monitoring campaign results with state-of-the-art behavioral models, only the Pigg model for Switch electric lighting Off agreed with observed behavior in the monitored offices. On the contrary, the control patterns suggested by Hunt, Haldi and Inkarojrit behavioral models were not confirmed during offices observation.

Overall, this study, though based on a small number of offices, highlights the benefits of monitoring real buildings to characterize behavioural reactions to environmental conditions, as well as the difficulty of correlating results with control patterns for electric lighting or shading derived from other monitoring campaigns and thus based on different experimental conditions. It also demonstrates that a much higher number of such studies is needed to gain confidence in the reliability and adequacy of control patterns, meant to be used in building simulation to assess energy and environmental performance.

The work also provide important implications for the practice of building simulation for energy-environmental assessment regarding occupants control pattern modelling. The key implications of the present study tend to be: i) that the adoption of electric lighting control patterns relying on daylight illuminance levels must be used with caution, since occupants have highly different ways to interact with electric lighting (including almost no interaction at all). In particular it seems that the models that determine electric lighting states at each simulation time step should be used only when there are/will be automatic controls installed; ii) in the cases when there is no automatic control of lighting, it would seem more realistic to relate the "switch Off" decisions to occupancy dynamics (especially to moments of arrival and departure from the office for short or long absences) than to re-evaluate them at every simulation time-step as a function of the environmental variables.

\section{ACKNOWLEDGMENTS}

This research was supported by the Portuguese Foundation for Science and Technology (Fundação para a Ciência e Tecnologia - FCT), under project PTDC/ENR/72597/2006 "Integrated evaluation of the impact of glazing and shading devices on the energy performance of Portuguese office buildings", hosted the Institute of Mechanical Engineering at the Faculty of Engineering of the University of Porto. The authors gratefully acknowledge the financial support of the Faculty of Engineering of the University of Porto, the Massachusetts Institute of Technology and the École Polytechnique Fédérale de Lausanne. The authors would also like to thank the full cooperation of the occupants of the offices monitored in the Faculty of Psychology and the Faculty of Engineering of the University of the Porto, as well as of the governing bodies of these institutions. 
Published as: P. Correia da Silva, V. Leal, M. Andersen, Occupants interaction with electric lighting and shading systems in real single-occupied offices: Results from a monitoring campaign, Building and Environment, vol. 64, pp. 152-168, 2013 (DOI: http://dx.doi.org/ 10.1016/j.buildenv.2013.03.015)

\section{REFERENCES}

Bourgeois, D., C. Reinhart, et al. (2005). Assessing the total energy impact of occupant behavioural response to manual and automated lighting systems. Ninth International IBPSA Conference. Montreal: 1-8.

Boyce, P. and P. Raynham (2009). The SLL Lighting Handbook, The Society of Light \& Lighting.

Boyce, P. R. and N. H. Eklund (1995). Evaluating lighting quality. 3rd European Conference on Energy-Efficient Lighting, Newcastle-upon-Tyne, UK.

Bullow-Hube, H. (2000). Office workers preferences of exterior shading devices: A pilot study. Eurosun 2000. Copenhagen, Denmark.

Canon (2009). Canon EOS50D Instruction Manual.

CEN (2008). EN ISO 13790 Energy performance of buildings - Calculation of energy use for

space heating and cooling, European Commitee for Standardization.

Christoffersen, J. and J. Wienold (2003). Monitoring procedure for assessment of user reaction to glare. Report ECCO-DBUR-0303-01, Danish Building and Urban Research - Energy and Indoor Climate Division.

Clarke, J. A. (2001). Energy simulation in building design. Bristol, ButterworthHeinemann.

Collins, B., W. Fisher, et al. (1990). "Second-level post-occupancy evaluation analysis." Journal of the Illuminating Engineering Society: 21-36.

Correia da Silva, P., V. Leal, et al. (2012). "Influence of shading control patterns on the energy assessment of office spaces." Energy and Buildings 50: 35-48.

Devore, J. L. (2011). Probability and Statistics for Engineering and the Sciences, Brooks/Cole, Cengage Learning.

Dumortier, D., B. Coutelier, et al. (2005). Photolux: A new luminance mapping system based on Nikon Coolpix digital cameras. Lux Europa 2005, Berlin, Germany.

Foster, M. and T. Oreszczyn (2001). "Occupant control of passive systems: the use of Venetian blinds." Building and Environment 36(2): 149-155.

Guimarães, R. C. and J. A. S. Cabral (2007). Estatística, McGraw-Hill.

Haldi, F. and D. Robinson (2009). A compreensive stochastic model of blind usage: Theory and validation. Eleventh International IBPSA Conference. Glasgow, Scotland.

Haldi, F. and D. Robinson (2010). "Adaptive actions on shading devices in response to local visual stimuli." Journal of Building Performance Simulation 3(2): 135-153.

Heschong, L., D. Aumann, et al. (2003). Windows and offices: A Study of office worker performance and the indoor environment, California Energy Commission.

Hunt, D. R. G. (1979). "The use of artificial lighting in relation to daylight levels and occupancy." Building and Environment 14(1): 21-33.

Hunt, D. R. G. and V. H. C. Crisp (1978). "Lighting controls: Their current use and possible improvement." International Journal of Energy Research 2(4): 343-374.

Inanici, M. N. (2006). "Evaluation of high dynamic range photography as a luminance data acquisition system." Lighting Research and Technology 38(2): 123-134.

Inkarojrit, V. (2005). Balancing comfort: Occupants' control of window blinds in private offices, University of California. PhD thesis.

Inkarojrit, V. (2008). "Monitoring and modelling of manually-controlled Venetian blinds in private offices: a pilot study." Journal of Building Performance Simulation 1(2): 75-89.

Inoue, T., T. Kawase, et al. (1988). The development of an optimal control system for window shading devices based on investigations in office buildings. ASHRAE Transactions 104: 1034-1049.

Kipp\&Zonen (2009). SP Lite2 Calibration Certificate.

Lee, E. S. and S. E. Selkowitz (1995). The design and evaluation of integrated envelope and lighting control strategies for commercial buildings. ASHRAE 1995 Winter Meeting. Chicago, IL, ASHRAE. 
Published as: P. Correia da Silva, V. Leal, M. Andersen, Occupants interaction with electric lighting and shading systems in real single-occupied offices: Results from a monitoring campaign, Building and Environment, vol. 64, pp. 152-168, 2013 (DOI: http://dx.doi.org/ 10.1016/j.buildenv.2013.03.015)

Levine, M. and D. Ürge-Vorsatz (2007). IPCC Fourth assessment report: residential and commercial buildings. IPCC Fourth assessment report.

LFC. (2011). "Building Physics Laboratory (LFC), Department of Civil Engineering, Faculty of Engineering of the University of Porto." from http://www.fe.up.pt/ lfcscc.

Mahdavi, A. and C. Proglhof (2009). User behavior and energy performance in buildings. IEWT - Internationale Energiewirtschaftstagung. Wien, Austria.

MathWorks (2009). Matlab 2009 Documentation, MathWorks.

Moore, T., D. J. Carter, et al. (2002). User attitudes toward occupant controlled office lighting. Lighting Research and Technology. 34: 207-216.

Muneer, T. (2004). Solar Radiation and Daylight Models. Oxford, Elsevier ButterworthHeinemann.

Nabil, A. and J. Mardaljevic (2005). "Useful daylight illuminance: a new paradigm for assessing daylight in buildings." Lighting Research and Technology 37(1): 41-57.

Newsham, G. R. (1994). Manual Control of Window Blinds and Electric Lighting: Implications for Comfort and Energy Consumption. Indoor and Built Environment. 3: 135-144.

O'Brien, W., K. Kapsis, et al. (2013). "Manually-operated window shade patterns in office buildings: A critical review." Building and Environment 60(0): 319-338.

Pallant, J. (2001). SPSS Survival Manual: A Step by Step Guide to Data Analysis Using the SPSS Program, Allen \& Unwin.

Pérez-Lombard, L., J. Ortiz, et al. (2008). "A review on buildings energy consumption information." Energy and Buildings 40(3): 394-398.

Pigg, S., M. Eilers, et al. (1996). Behavioral Aspects of Lighting and Occupancy Sensors in Privates Offices: A case study of a University Office Building. ACEEE 1996 Summer Study on Energy Efficiency in Buildings 8.

Rea, M. S. (2000). Lighting Handbook: Reference and application. New York, Illuminating Engineering Society of North America.

Reinhart, C. F. (2004). "Lightswitch-2002: a model for manual and automated control of electric lighting and blinds." Solar Energy 77(1): 15-28.

Reinhart, C. F. and K. Voss (2003). "Monitoring manual control of electric lighting and blinds." Lighting Research and Technology 35(3): 243-260.

Roche, L. (2002). "Summertime performance of an automated lighting and blinds control system." Lighting Research and Technology 34(1): 11-25.

Roche, L., E. Dewey, et al. (2000). Occupant reactions to daylight in offices. Lighting Research and Technology. 32: 119-126.

RSECE (2006). Regulamento dos Sistemas Energéticos de Climatização em Edificios (Regulation of the Buildings Air Conditioning Energy Systems), Ministry of Public Works, Tansportation and Communications. Decree-Law n 79/2006 of April 4.

Skyelnstruments (2010). High output sensors specifications.

Sutter, Y., D. Dumortier, et al. (2006). "The use of shading systems in VDU task offices: A pilot study." Energy and Buildings 38(7): 780-789.

ThiesClima (2010). Hygro-thermo transmitter compact technical data

Van Den Wymelenberg, K. (2012). "Patterns of occupant interaction with window blinds: A literature review." Energy and Buildings 51(0): 165-176.

Veitch, J. A. and G. R. Newsham (1995). Quantifying lighting quality based on experimental investigations of end user performance and preference. 3rd European Conference on Energy-Efficient Lighting, Newcastle-upon-Tyne, UK.

Velds, M. (2000). Assessment of lighting quality in office buildings with daylighting systems, Technical University of Delft. PhD thesis.

Velds, M. and J. Christoffersen (2001). Monitoring procedures for the assessment of daylighting performance of buildings. IEA SHC Task 21 "Daylight in Buildings" I ECBCS Annex 29, International Energy Agency.

Wienold, J. (2009). Dynamic daylight glare evaluation. Eleventh International IBPSA Conference. Glasgow, Scotland. 
Published as: P. Correia da Silva, V. Leal, M. Andersen, Occupants interaction with electric lighting and shading systems in real single-occupied offices: Results from a monitoring campaign, Building and Environment, vol. 64, pp. 152-168, 2013 (DOI: http://dx.doi.org/ 10.1016/j.buildenv.2013.03.015)

Wienold, J. and J. Christoffersen (2006). "Evaluation methods and development of a new glare prediction model for daylight environments with the use of CCD cameras." Energy and Buildings 38(7): 743-757. 